\title{
ATLAS DE MEDICINA NUCLEAR EN NEFROUROLOGÍA
}

\section{Leonardo Cadavid Blanco*}

El riñón es un órgano con sofisticados sistemas funcionales cuyas alteraciones no pueden ser detectadas en forma exclusiva por imágenes es-tructurales. La pielonefritis es un ejemplo. Durante muchos años se ha sobrediagnosticado, pues no pudo documentarse hasta la aparición del ácido dimercap-tosuccínico (DMSA); este ácido no se deposita en túbulos renales inflamados. Hoy en día disponemos de radiotrazadores glomerulares, tubulares, mixtos, de unión, inflamatorios, tumorales y de receptores. Estos estudios no producen alergias, no requieren preparación intestinal ni están contraindicados en insuficiencia renal. Permiten realizar cuantificaciones globales, diferenciales y porcentuales con representación gráfica, no son invasores y proporcionan una baja tasa de radiación. Son estudios esencialmente funcionales. No se puede desconocer que los cambios funcionales preceden a los estructurales.

\section{Estudios normales}

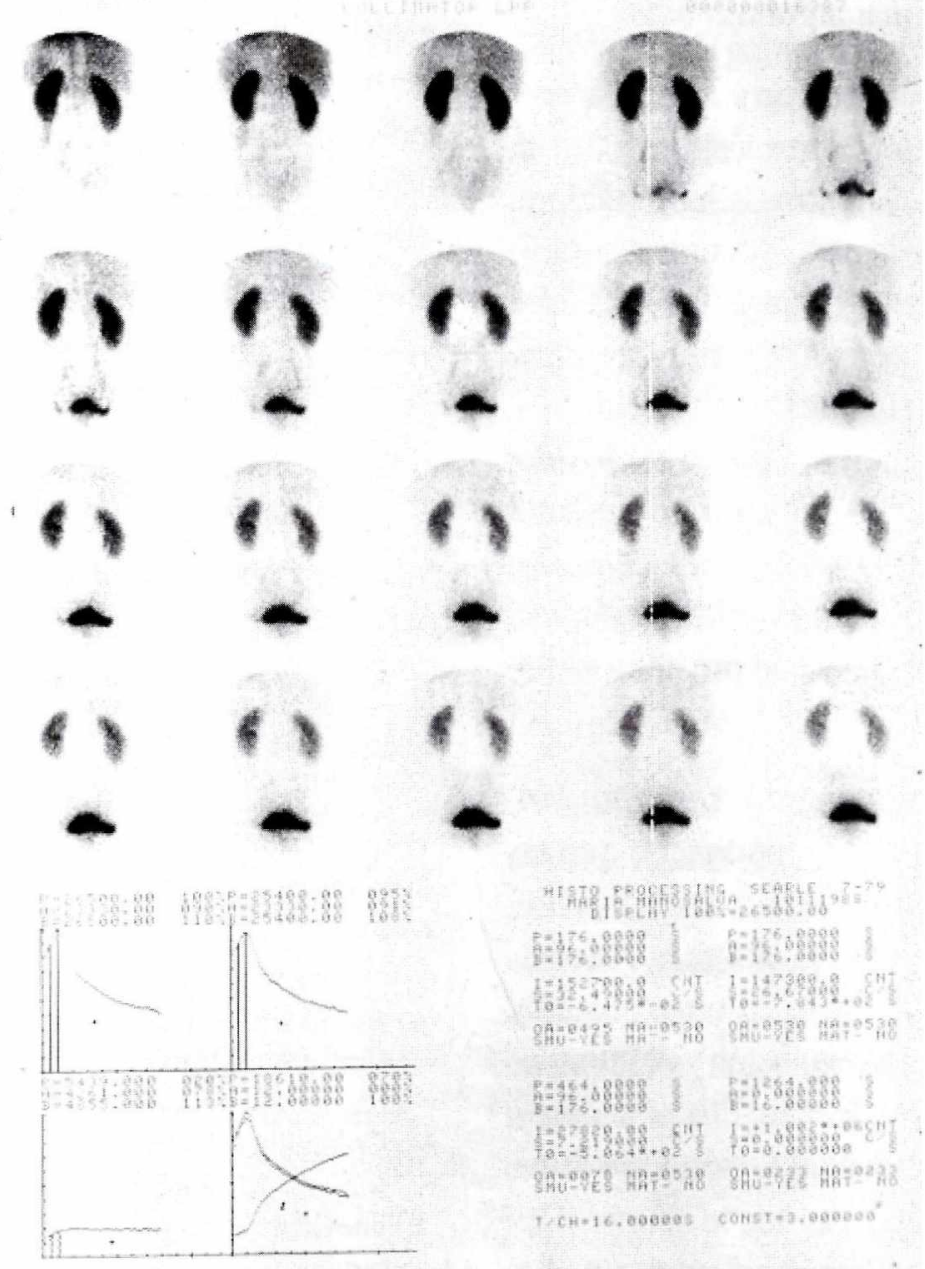

Figura I. Renograma normal con 99mTcDTPA (dietilen triamino pentacético), agente glomerular, histograma con sus tres segmentos normales; se aprecian los riñones y la vejiga, los uréteres no se visualizan y el fondo corporal es limpio. Este radiofármaco nos permite además medir la tasa de filtración glomerular.

\footnotetext{
* Jefe del Servicio de Medicina Nuclear, Hospital de San José de Bogotá,

Profesor Asociado Fundación Universitaria de Ciencias de la Salud.
} 


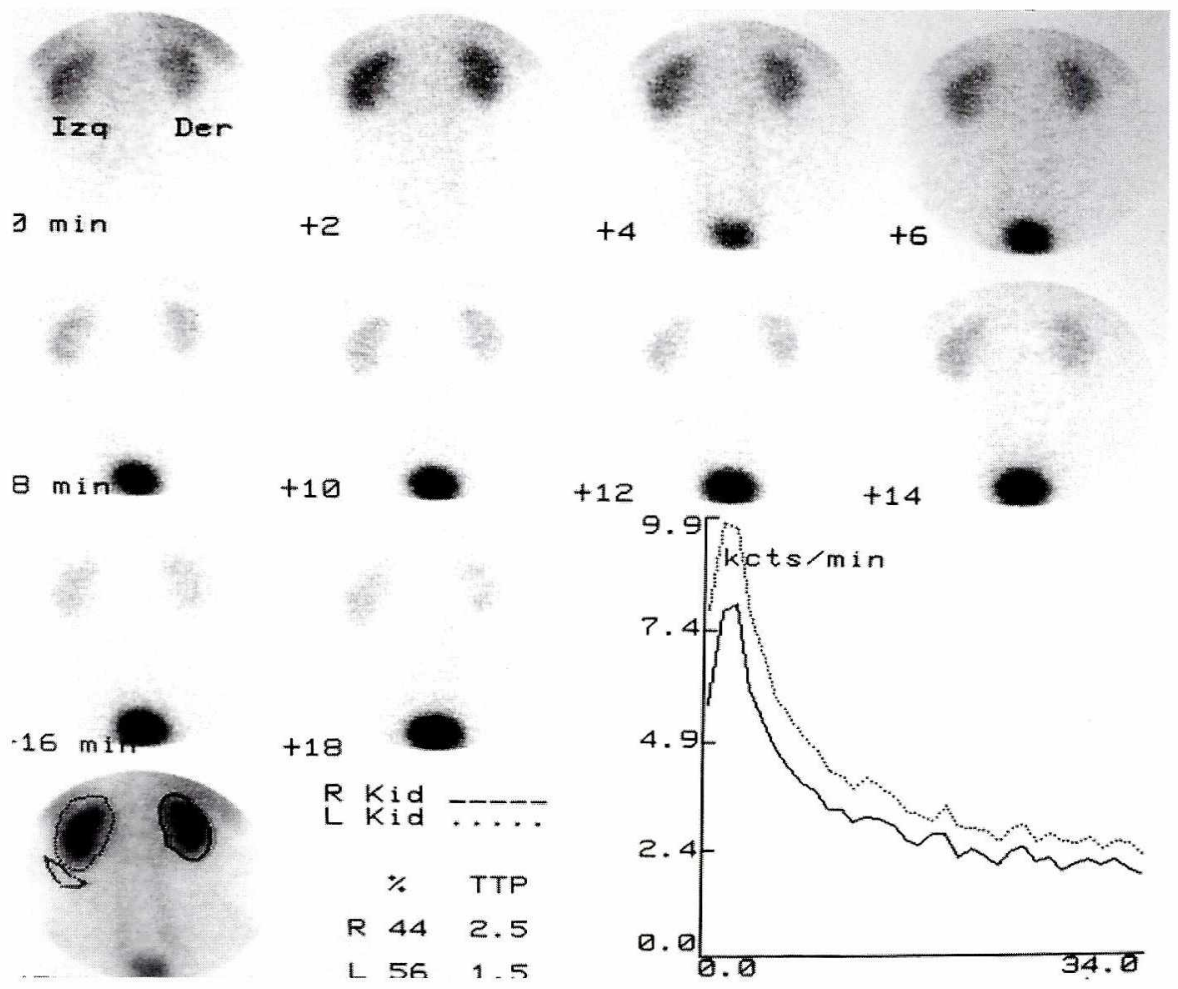

Figura 2. Renograma normal con $99 \mathrm{mTcDTPA}$, detalle del histograma. El primer segmento es una pendiente absoluta y refleja la perfusión, el segundo segmento es una pendiente entre $45^{\circ}$ y $60^{\circ}$, indica la eficiencia de la depuración y el tercer segmento es una curva exponencial con caída suave. El T máximo corresponde al pico de mayor radioactividad y ocurre entre el segundo y tercer minuto, el T/2 es el tiempo que se toma cada riñón en disminuir su radioactividad en un $50 \%$ lo que por lo regular ocurre en el séptimo minuto.
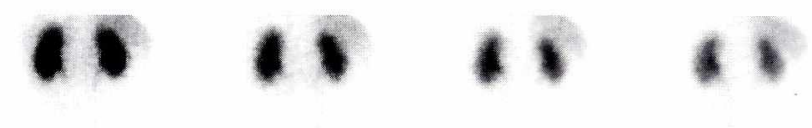

min

$+2$

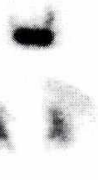

$+4$

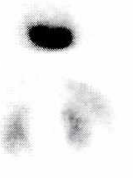

$+5$
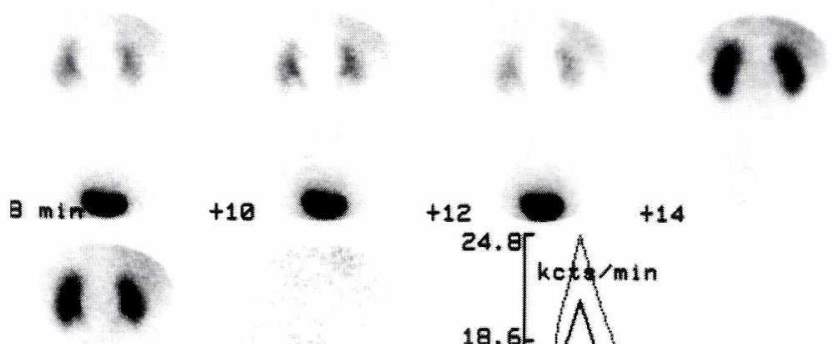

$+10$
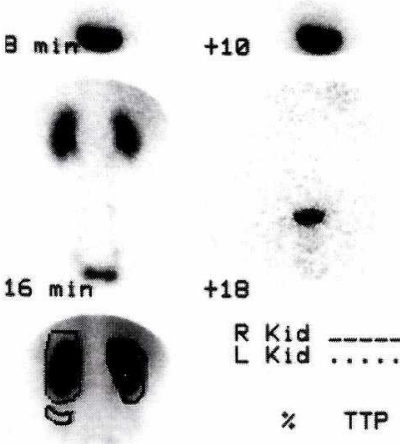
$+18$

R Kid Kid ...... * TTP

R $46 \quad 2.5$

L $54 \quad 2.5$

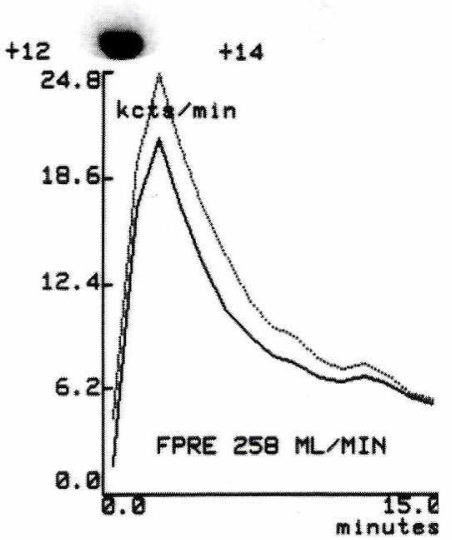

Figura 3. Renograma normal con 99mTcMAG3 (mercaptoacetiltriglicina), agente tubular, permite medir la tasa de flujo plasmático renal. Observe su rápida excreción, los sistemas colectores se ven con mayor claridad que con el DTPA. En nuestro medio, es el agente de elección en uropatía obstructiva con falla renal. 

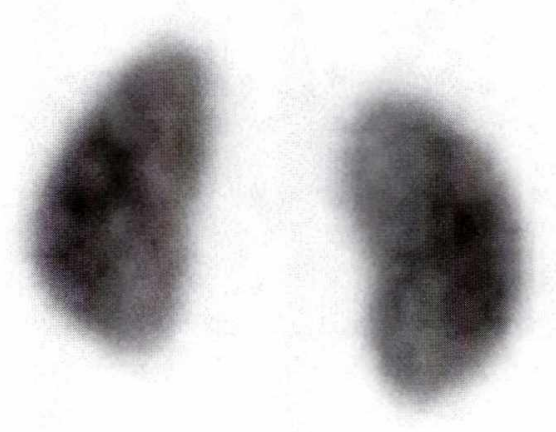

Figura 4. Gamagrafía renal estática o cortical normal con 99mTcDMSA, agente de fijación al epitelio tubular. Imágenes obtenidas tres horas después de la inyección, el trazador se concentra un $60 \%$ de la dosis administrada en los grupos sulfidrilos de la célula tubular en forma análoga a como lo hacen las sales mercuriales, pero sin su toxicidad.

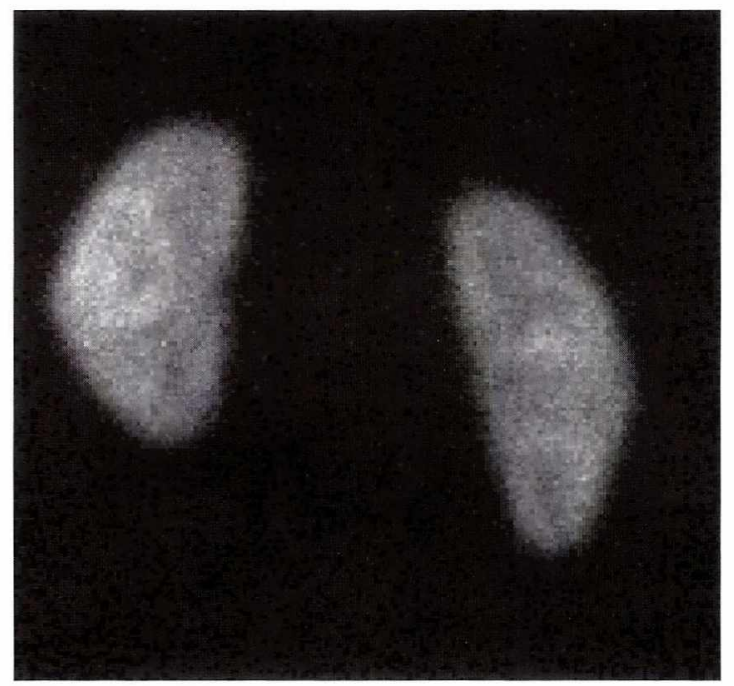

Figura 5. Gamagrafía renal con 99mTc DMSA en un adulto sano. Se pueden ver las columnas de Bertin entre las pirámides.

\section{Malformaciones congénitas}

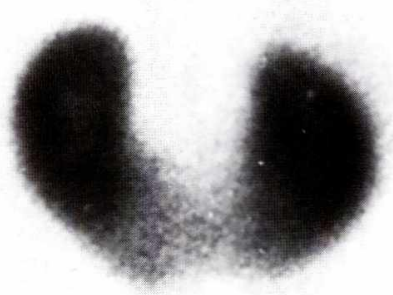

6a

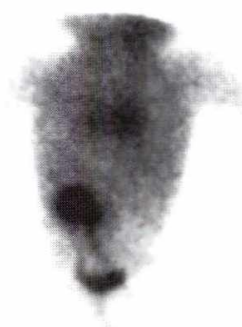

6d

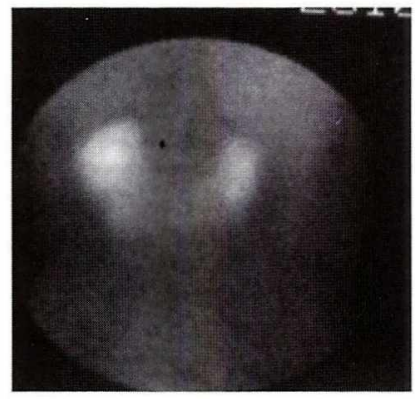

6b

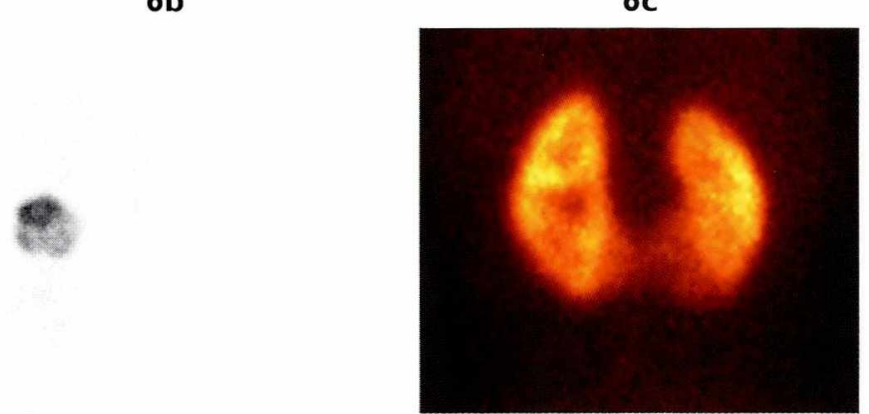

6e

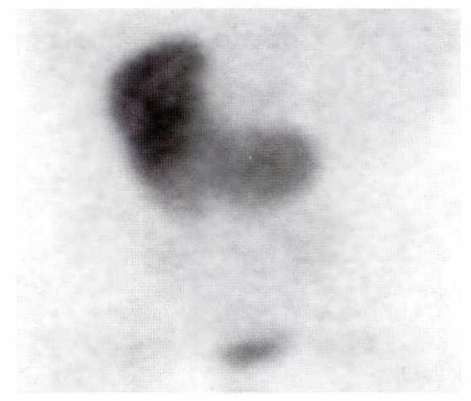

6c

$6 f$

Figura 6. Defectos de la migración renal. 6a y 6b) Riñones en herradura. 6c) Riñones fusionados en línea media. 6d) Riñones con ectopía renal cruzada fusionada izquierda. 6e) riñones en torta (cake kidney) en el hipogastrio sobre línea media. 6f) Riñones en herradura. 


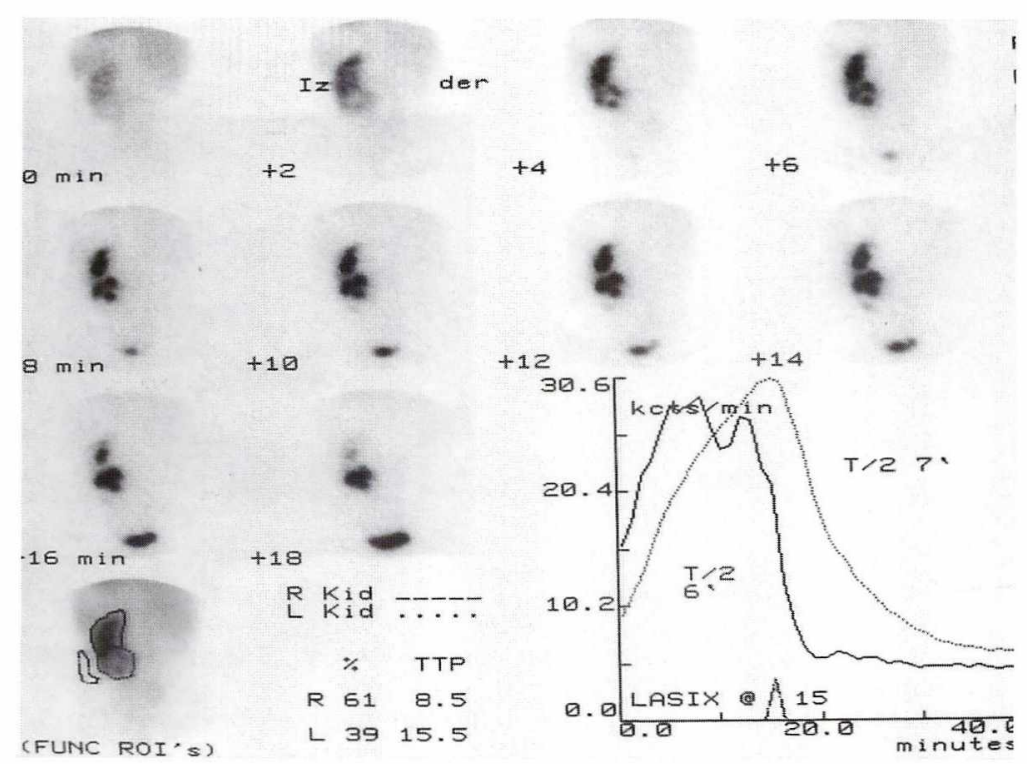

Figura 7. Ectopía renal cruzada fusionada con hidronefrosis en niña de 10 años con infecciones urinarias recurrentes.
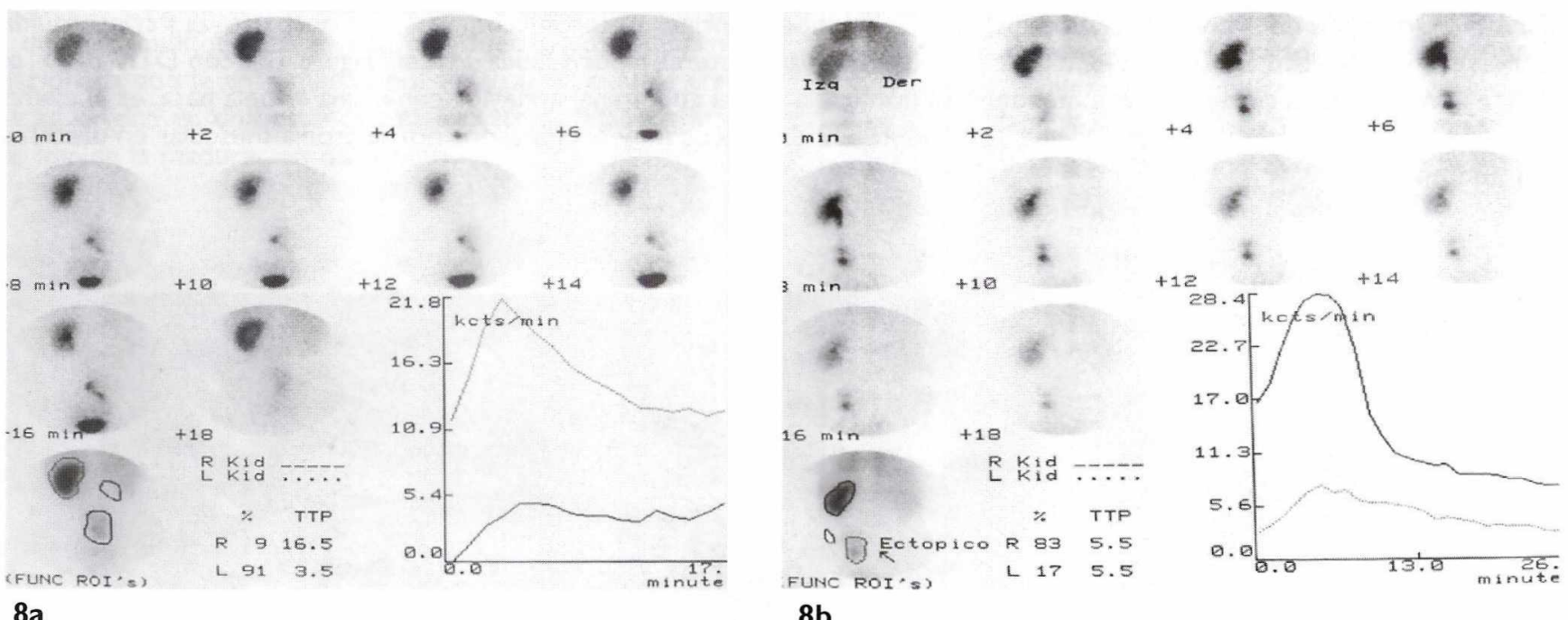

$8 a$

Figura 8. Dos casos de ectopía renal pélvica, imágenes. 8a) Sobre línea media y 8b) Cruzada.

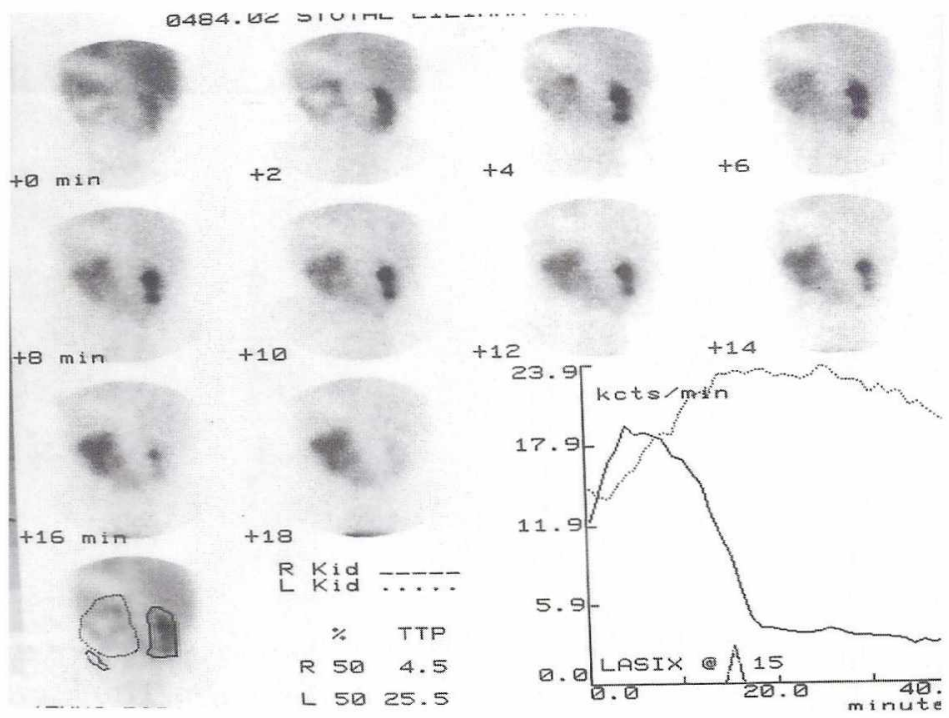

Figura 9. Hidronefrosis en riñones fusionados, mujer de 24 años con infecciones y cálculos. 99mTcDTPA. 

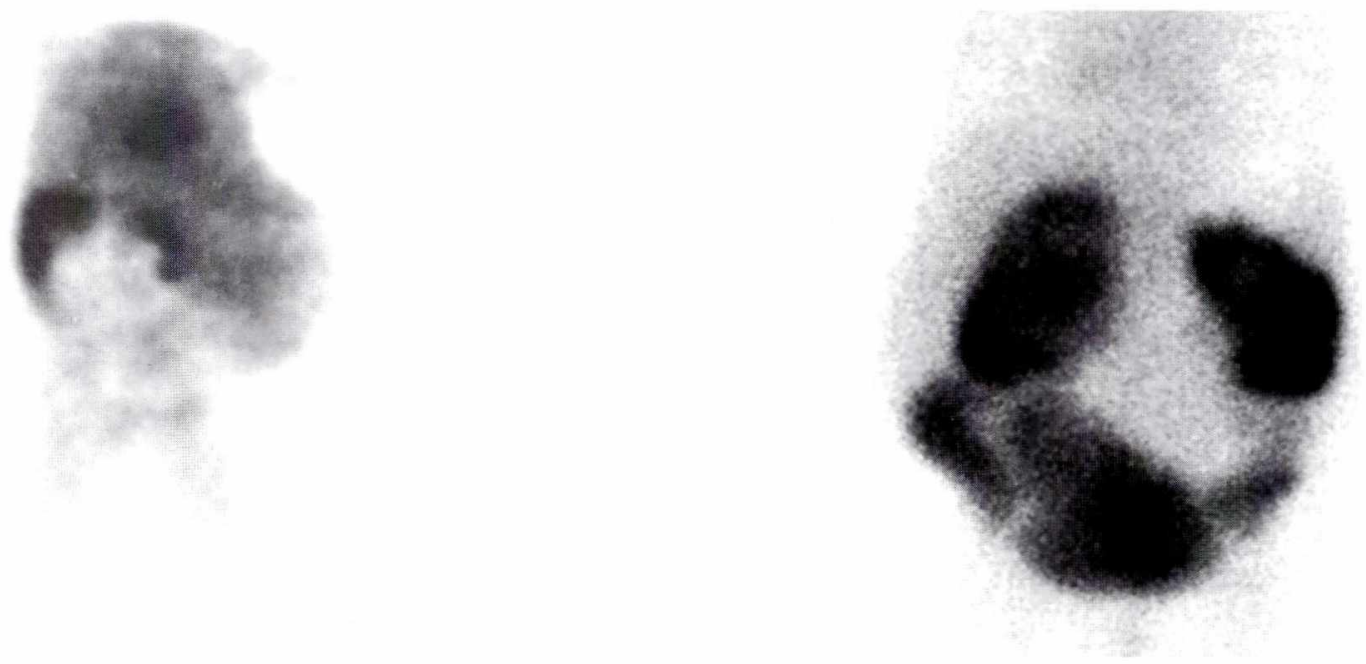

$10 \mathrm{a}$

$10 \mathrm{~b}$

Figura 10. Dos casos de prune-belly (ausencia de músculos abdominales, ureterohidronefrosis no obstructivas y criptorquídia). Obsérvese la deformidad abdominal, la dilatación y tortuosidad ureteral, hiporreflexia vesical. Figura I0a con DTPA, I0b con DMSA. Es una malformación masculina que debe su nombre a la piel abdominal arrugada como una ciruela pasa, es el ejemplo clásico de hidronefrosis no obstructiva, aunque presenta T/2 diuréticos muy prolongados por la atonía muscular en uréteres y pared abdominal.

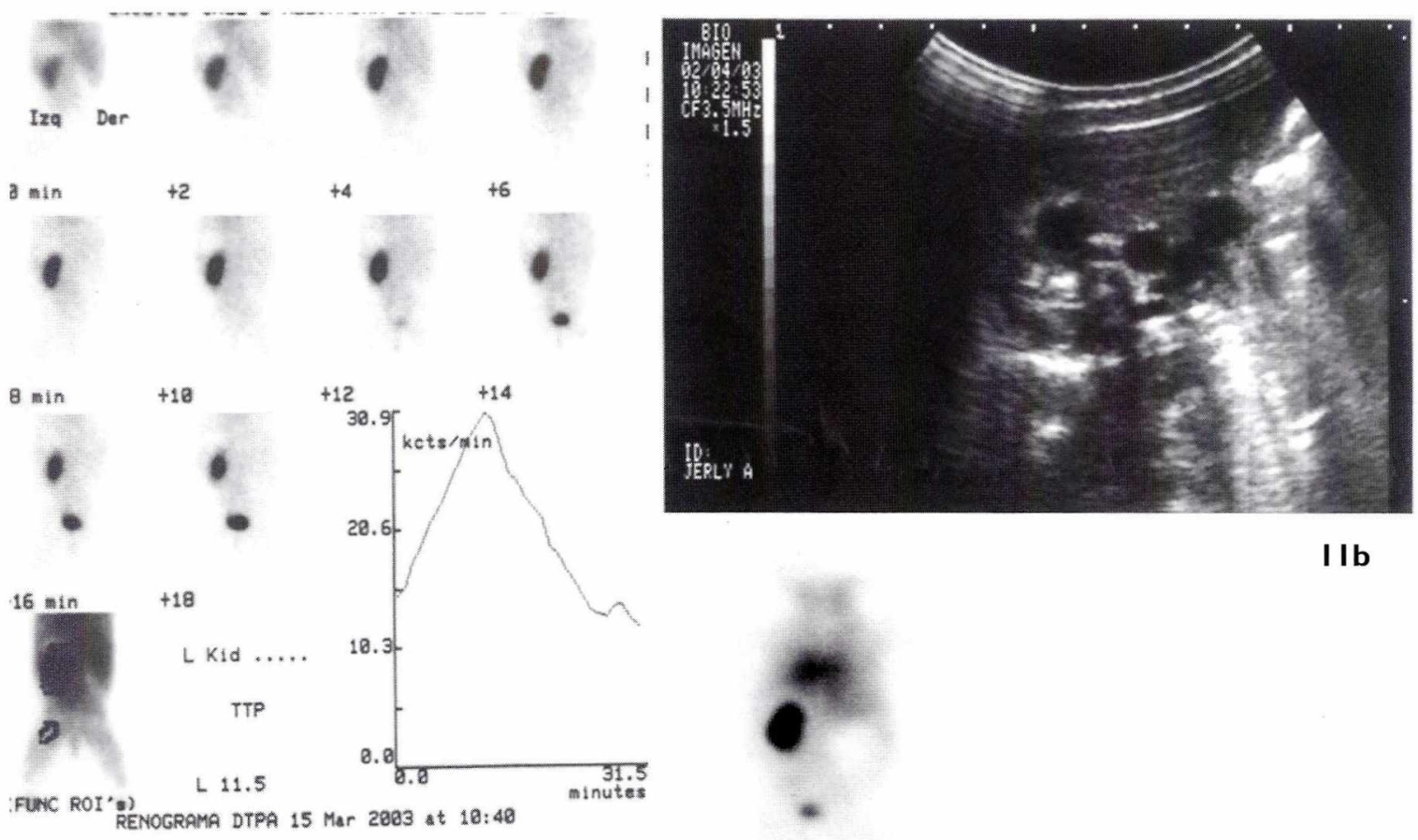

I la

I I c

Figura I I. Dos casos de displasia multiquística. Observe: falta de captación cortical, siempre es unilateral (la forma bilateral no es compatible con la vida). Figura I la) Displasia renal derecha en niña de 6 meses. I Ib) Ecografía del paciente anterior. I Ic) Displasia renal derecha en recién nacido con masa abdominal palpable, 99mTcDTPA. 


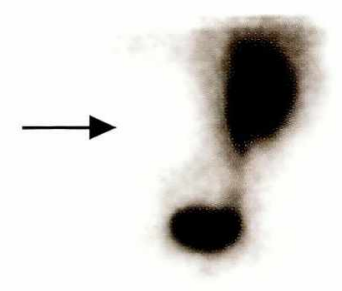

$12 \mathrm{a}$

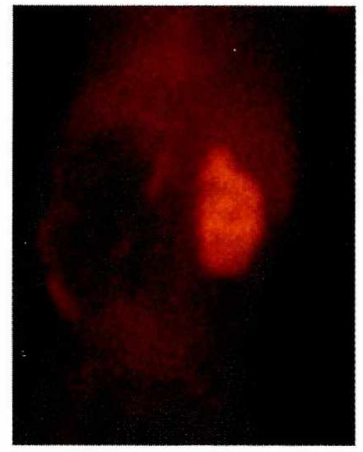

I2b

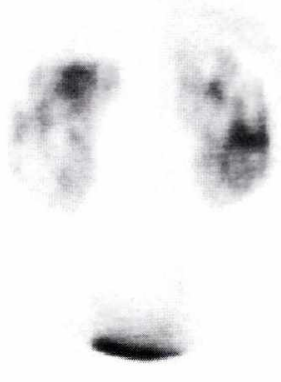

$13 a$
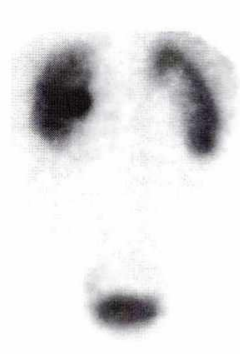

I3b
Figura 12. Displasia multiquística renal izquierda en recién nacido, 99mTc MAG3. Compare la falta de captación cortical de la figura 12a con la hidronefrosis y el adelgazamiento cortical de la figura $12 \mathrm{~b}$ correspondiente a una hidronefrosis. La displasia multiquística es una enfermedad congénita, no relacionada con la enfermedad poliquística, la cual se cree que se origina en una estenosis pieloureteral fetal extrema que impide la maduración de la nefrona.
Figura 13. Riñón poliquístico del adulto, defectos "fríos" corticales, sin relación con el sistema colector. Figura I3a) 99mTcDTPA. I3b) Hidronefrosis derecha, dilatación del sistema colector, sin lesiones corticales. Los riñones poliquísticos son de gran tamaño, siempre son bilaterales, es una enfermedad hereditaria con dos formas de presentación, la autosómica dominante (la más frecuente) que se expresa en la edad adulta y la otra es la forma recesiva que se le llama también infantil. Puede acompañarse de quistes hepáticos.

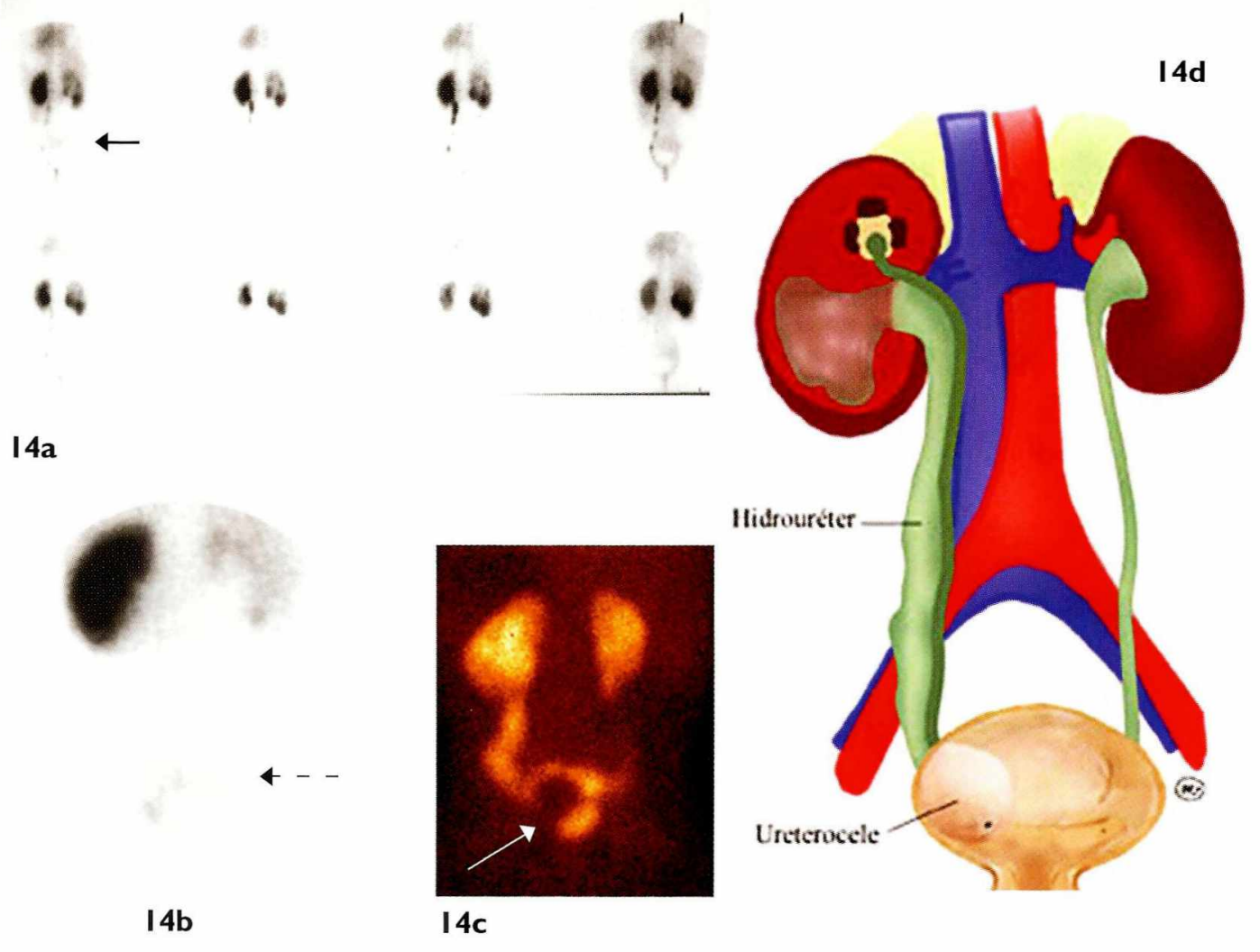

Figura 14. Ureteroceles derechos que producen ureterohidronefrosis. I4a, I4b) Obsérvese la lesión "fría” intravesical. I4c) Esquema de un ureterocele. Se caracterizan por ser casi siempre obstructivos y presentar una lesión hipocaptante en la vejiga. 
Figura 15. Agenesia renal izquierda, $99 \mathrm{mTCDTPA}$. Puede ser el resultado final de un riñón displásico que involuciona en forma espontánea, quedando el riñón contralateral sano.

\section{Doble sistema colector (duplicación)}

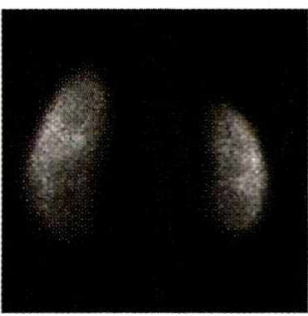

$16 a$
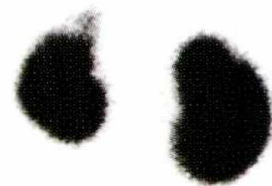

I6d

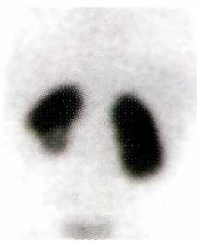

I6h

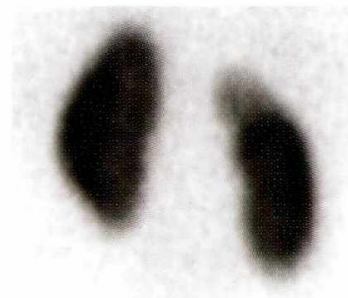

I6b

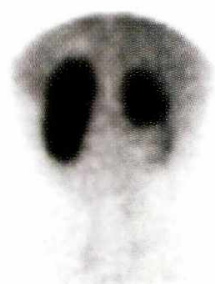

$16 e$
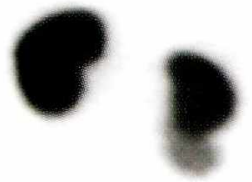

$16 \mathrm{i}$
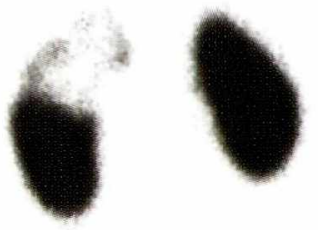

$16 c$

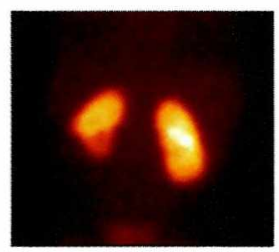

$16 f$

$16 \mathrm{~g}$
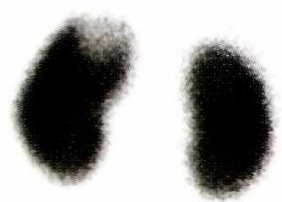

$16 \mathrm{j}$

Figura 16. Doble sistemas colectores (DSC). 16a) Doble sistema colector izquierdo en mujer de 32 años asintomática, el estudio solo muestra aumento renal izquierdo. 16b) DSC superior derecho. 16c) DSC en mitad superior del izquierdo. I6d) En polo superior izquierdo simulando un pequeña cicatriz. 16e) DSC en mitad inferior del derecho. I6f) Simulando una caliestasia o divertículo calicial. 16g) Con pérdida de volumen. 16h) mismo caso en escala de grises. I6i) en polo inferior derecho. 16j) en polo superior izquierdo. Los estudios e y fueron realizados con 99mTcDTPA, los demás son con 99mTcDMSA. EI DSC es la malformación renal más frecuente, su prevalencia es I por cada 450 nacidos vivos, la forma incompleta es asintomática, la completa se caracteriza por infecciones recurrentes e hidronefrosis segmentarias. Puede ser bilateral, las del polo superior tienden a ser obstructivos y las del polo inferior suelen ser refluyentes. Su manifestación clínica es la infección recurrente y la enuresis diurna. 


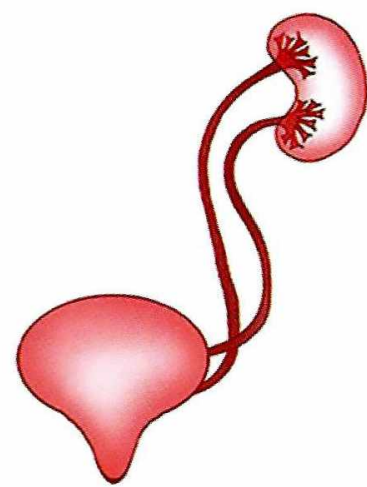

$17 \mathrm{a}$

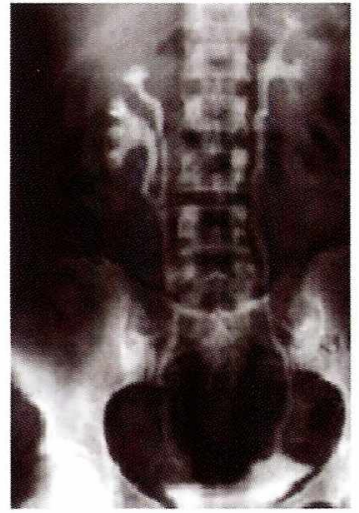

I7d

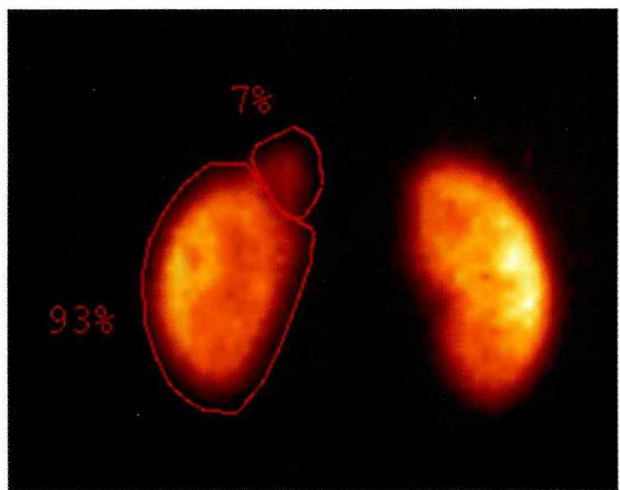

I $7 \mathrm{~b}$

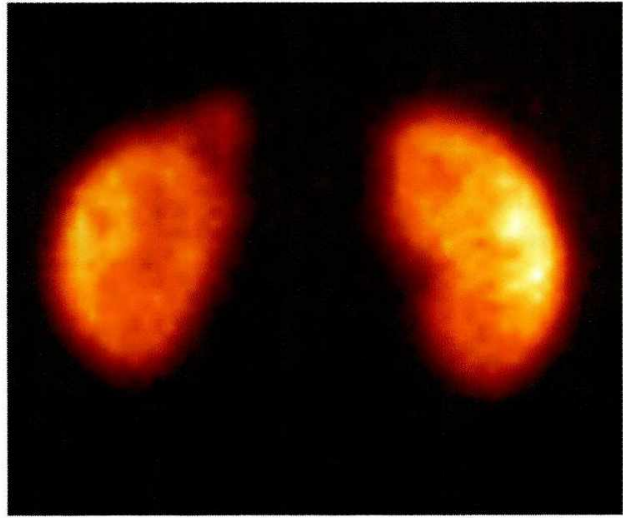

I7c

Figura I 7. Doble sistema colector superior derecho con $7 \%$ de función regional previa a polectomía superior con ureterectomía. Niña de 9 años con enuresis diurna e infecciones urinarias recurrentes. 17a) Esquema del DSC. I7b) Cuantificación regional, 17c) Gamagrafía renal con 99mTcDMSA. 17d) Urografía excretora de un DSC.

\section{Trauma renal}

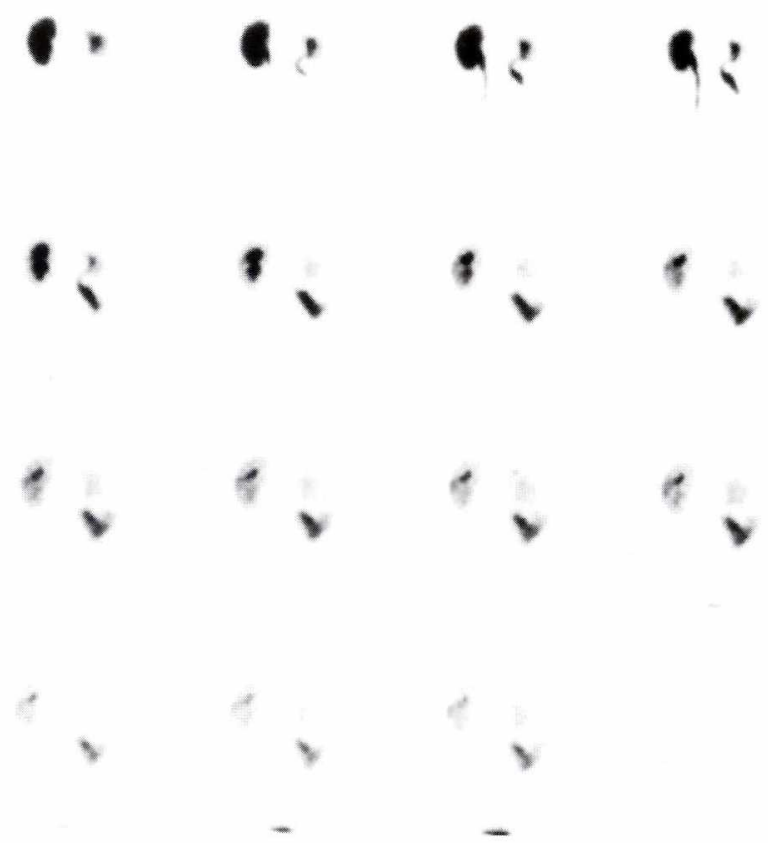

Figura I8. Fístula ureteral derecha complicación de linfadenectomía retroperitoneal por carcinoma de cervix, 99mTc DTPA. 


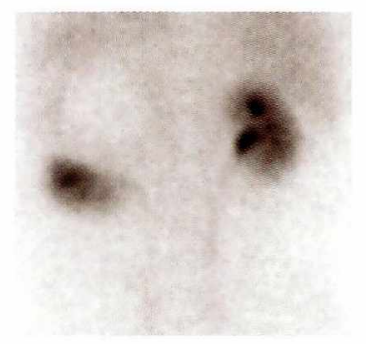

$19 \mathrm{a}$

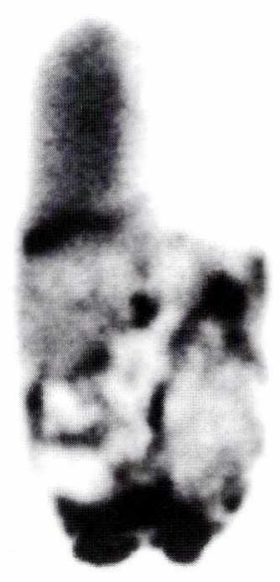

$20 a$

\section{Reflujo}

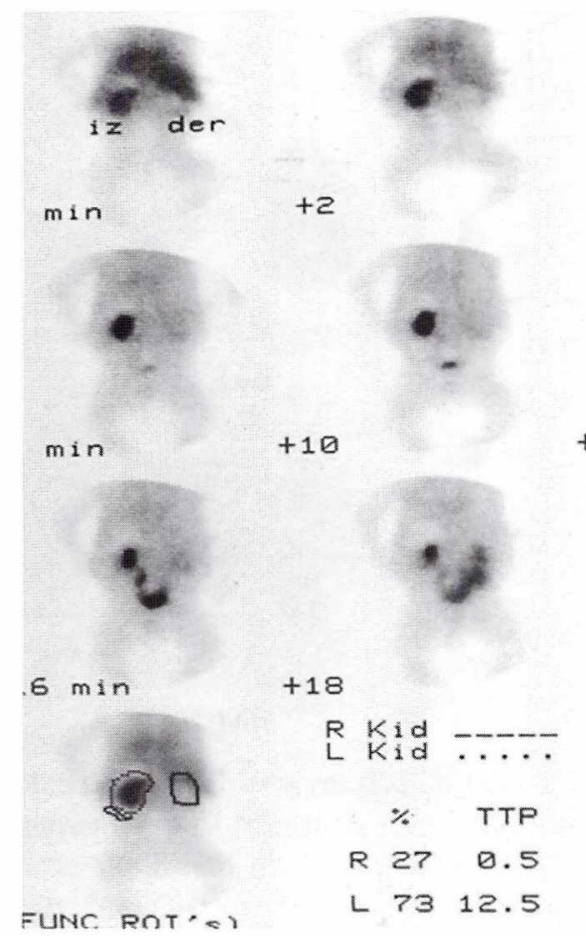

2 Ia
$19 b$
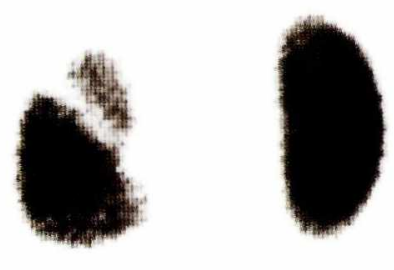

Figura 19. Trauma renal cerrado. 19a) Hematoma subcapsular en los dos tercios superiores del riñón izquierdo 99mTcDTPA. 19b) Virtual avulsión del polo superior izquierdo, 99mTcDMSA,

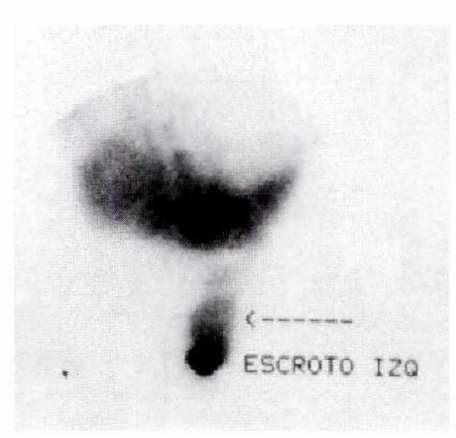

$20 b$
Figura 20. Peritoneografía nuclear. 20a) Fístula peritoneopleural derecha. 20b) Hernia inguinoescrotal directa e indirecta izquierda. Pacientes con dificultades en la iniciación del programa de diálisis peritoneal ambulatoria, 99mTcMAA por catéter peritoneal. 


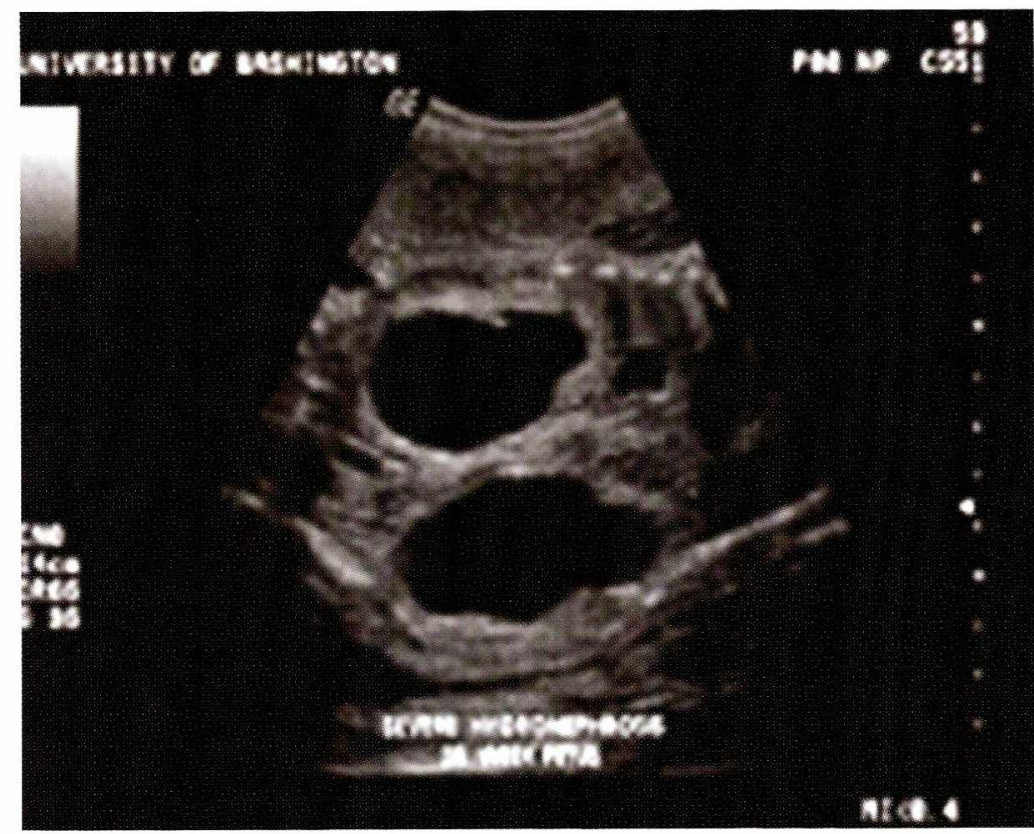

Figura 22. Hidronefrosis prenatal, ecografía.
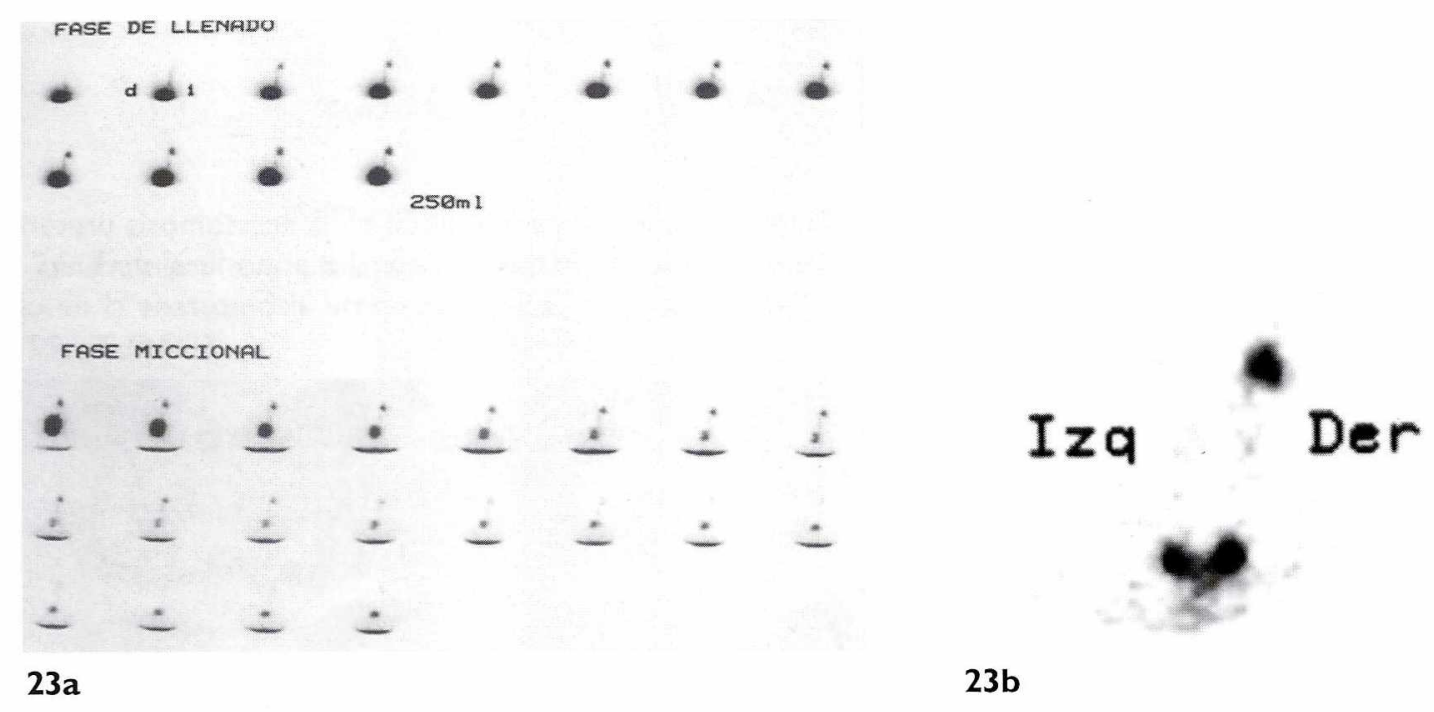

Figura 23. Nefropatía por reflujo. 23a) Cistografía nuclear con reflujo bilateral. 23b) Reflujo bilateral. 23c) Pielonefritis aguda y crónica bilateral, cicatrices y atrofia en el izquierdo, $99 \mathrm{mTcDMSA}$. 


\section{Trasplante renal}

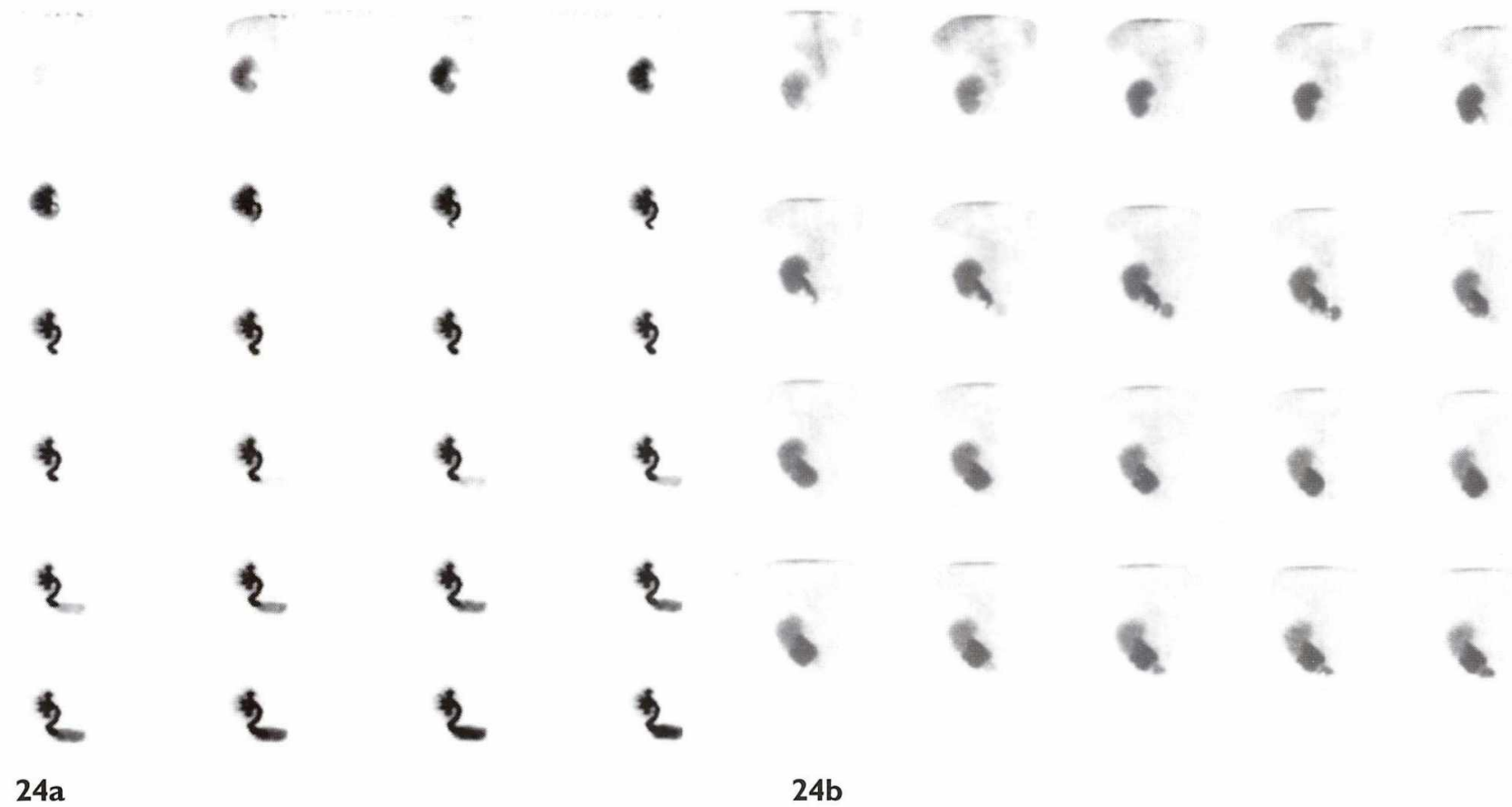

Figura 24. Trasplante renal con complicaciones "quirúrgicas". 24a) Estenosis ureteral distal en la anastomosis ureterovesical. 24b) Urinoma paraureteral por fístula ureterovesical, la cual se corrigió con una sonda uretral durante una semana.

$25 \mathrm{a}$

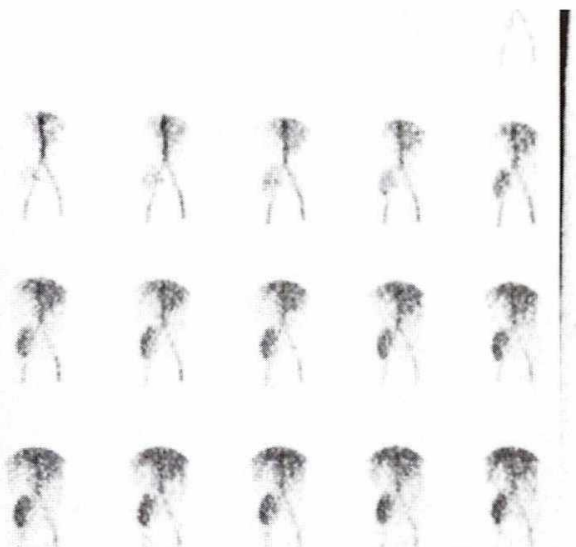

$25 b$

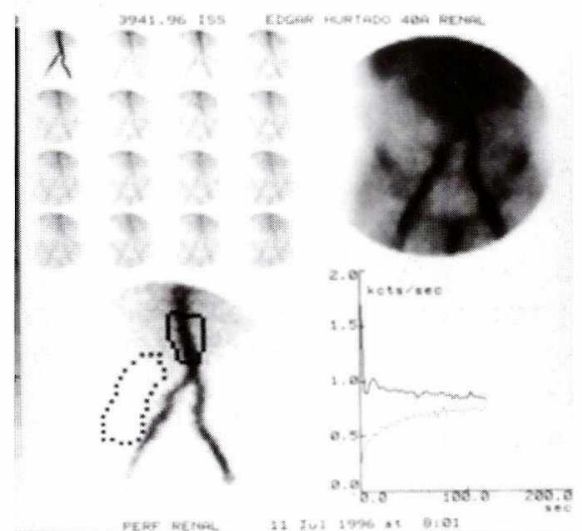

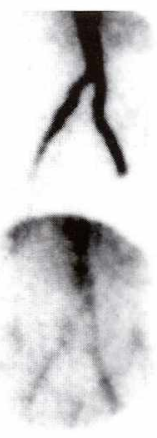
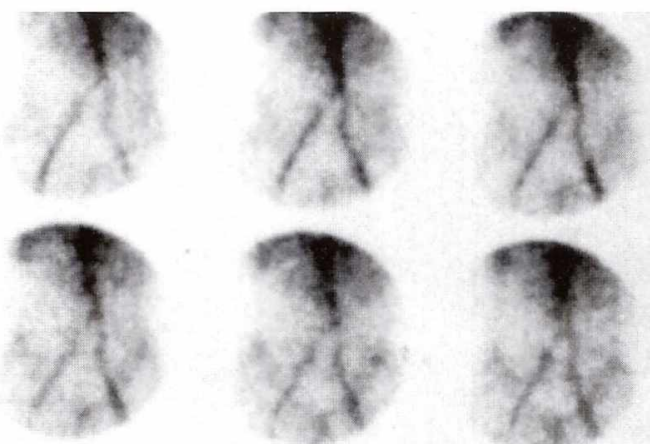

$25 c$
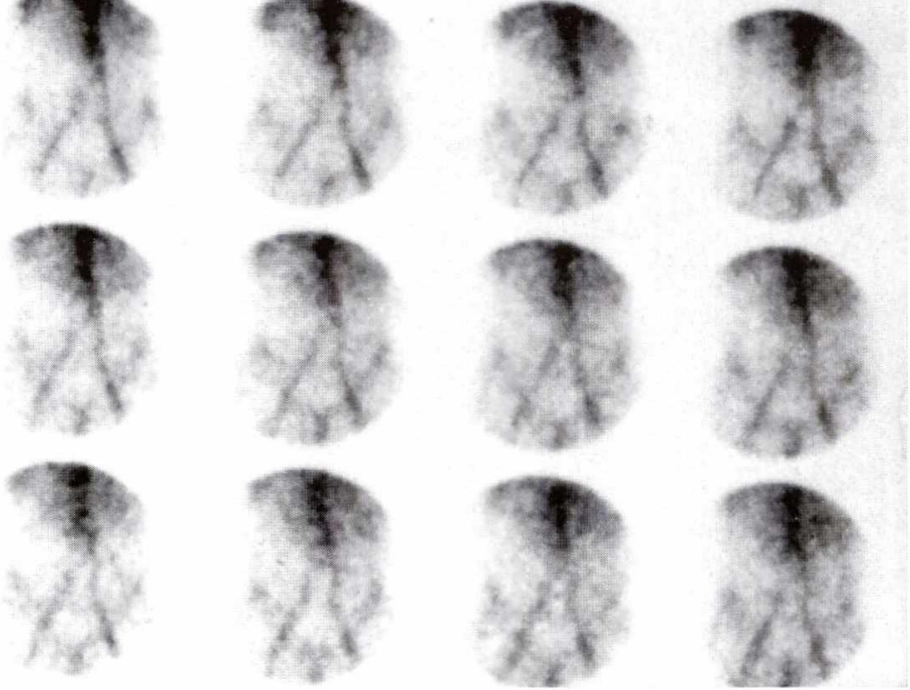

Figura 25. Trasplante renal. 25a) Perfusión renal normal en insuficiencia renal por necrosis tubular aguda, lo cual excluye el rechazo como causa de la insuficiencia. 25b) Ausencia de perfusión renal en rechazo agudo. 25c) Renograma en rechazo agudo. 


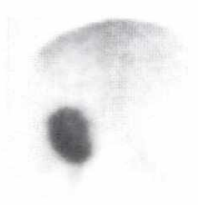

Din

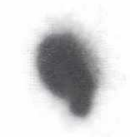

$16 \mathrm{~min}$

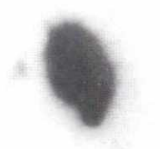

$32 \mathrm{~min}$

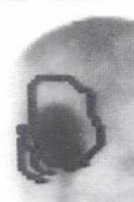

(FUNC ROT"s)

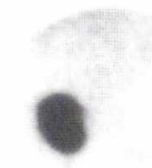

$+4$

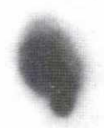

$+20$

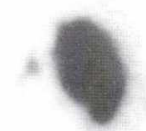

$+36$

R Kid

TTP

R 39.5

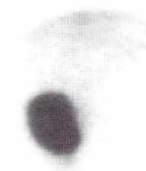

$+8$ $+12$
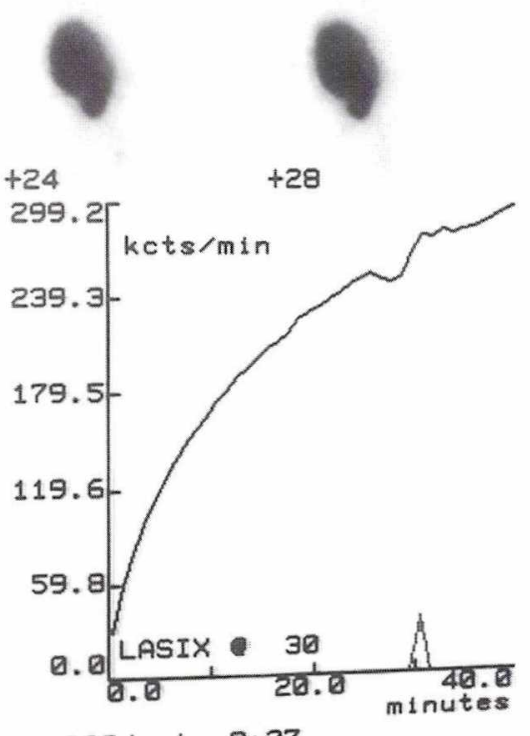

Figura 26. Fístula urinaria en postrasplantado renal con creatinina de $8 \mathrm{mg} / \mathrm{dL}$. El estudio reveló escape urinario a piel originado en la anastomosis ureterovesical. El escaso paso del trazador a vejiga se debe exclusivamente a orina de riñones nativos, 99mTcMAG3.

\section{Hipertensión renovascular}
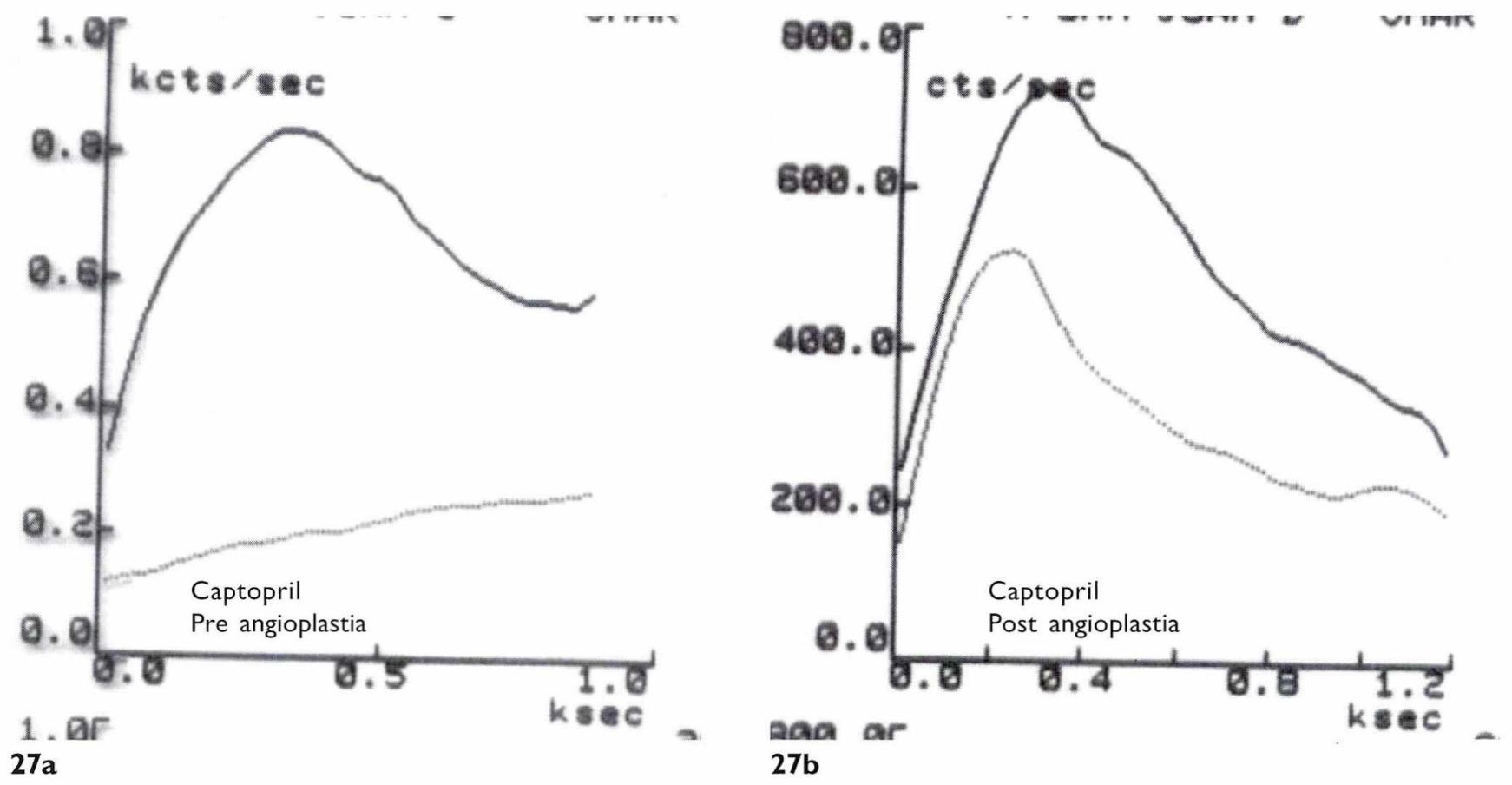

Figura 27. Renograma con captopril. 27a) Compromiso unilateral inducido por inhibidores de la enzima convertidora de angiotensina (IECA). 27b) Desaparece el efecto luego de angioplastia. 

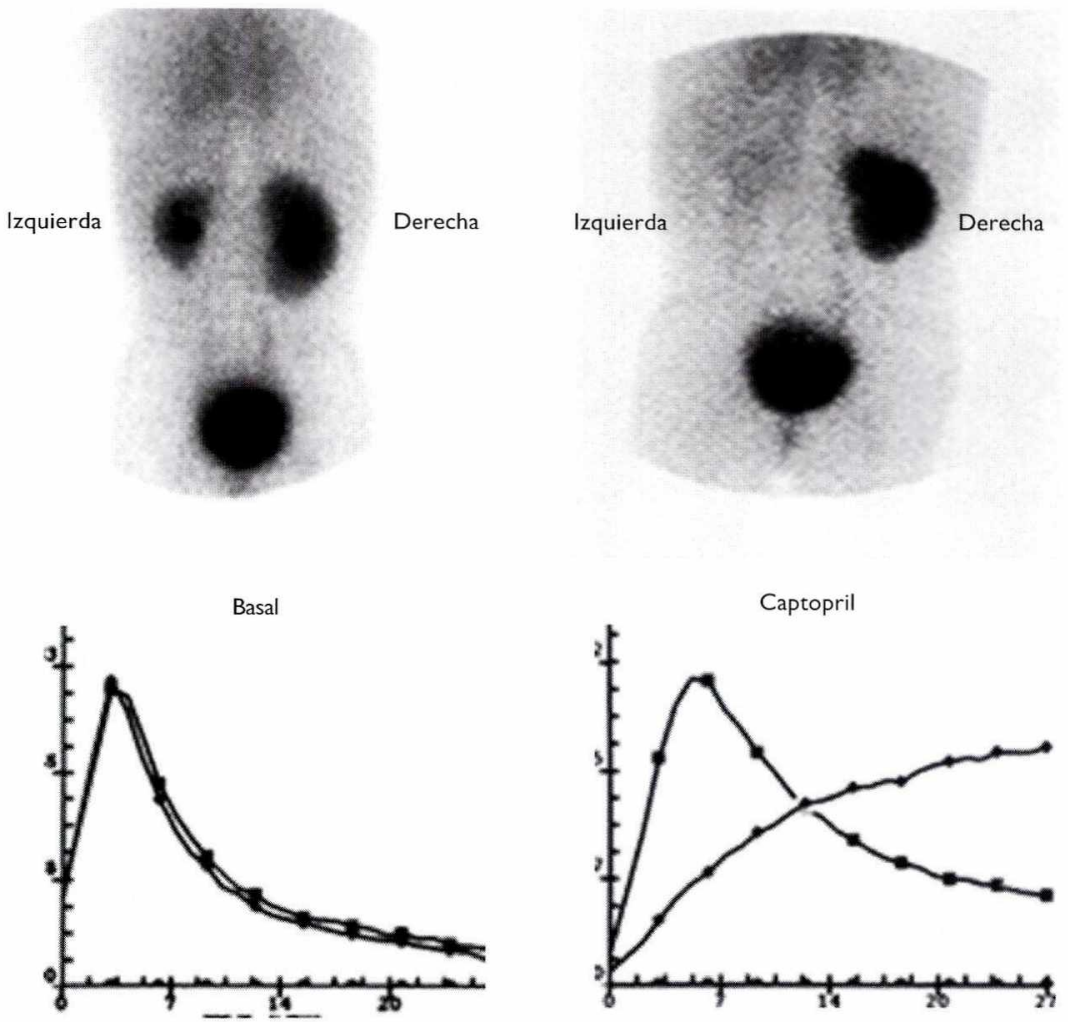

Figura 28. Renograma basal y con captopril en hipertensión renovascular. 28a) El riñón izquierdo es pequeño pero funciona, $28 \mathrm{~b}$ el riñón izquierdo se excluye por efecto del captopril.
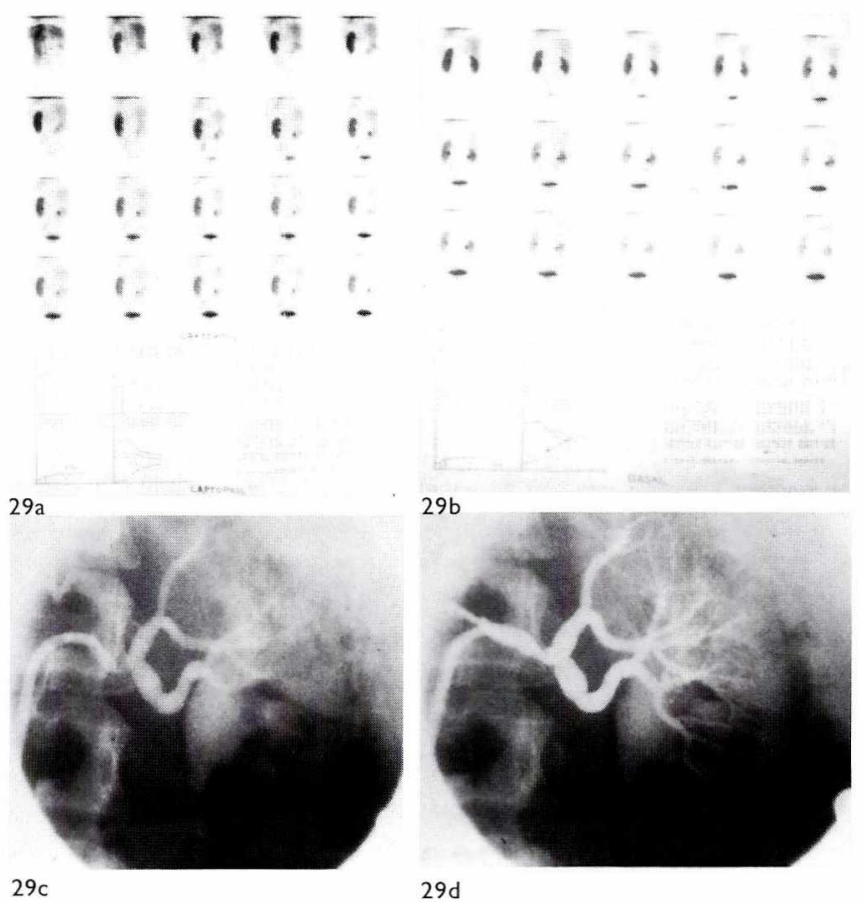

Figura 29. Renograma basal y con captopril. 29a) Riñón con enfermedad renovascular derecha excluído por IECA. 29b) sin captopril la función derecha se restablece. 29c) Estenosis arteria renal. 29d) Arteriografía renal post angioplastia.

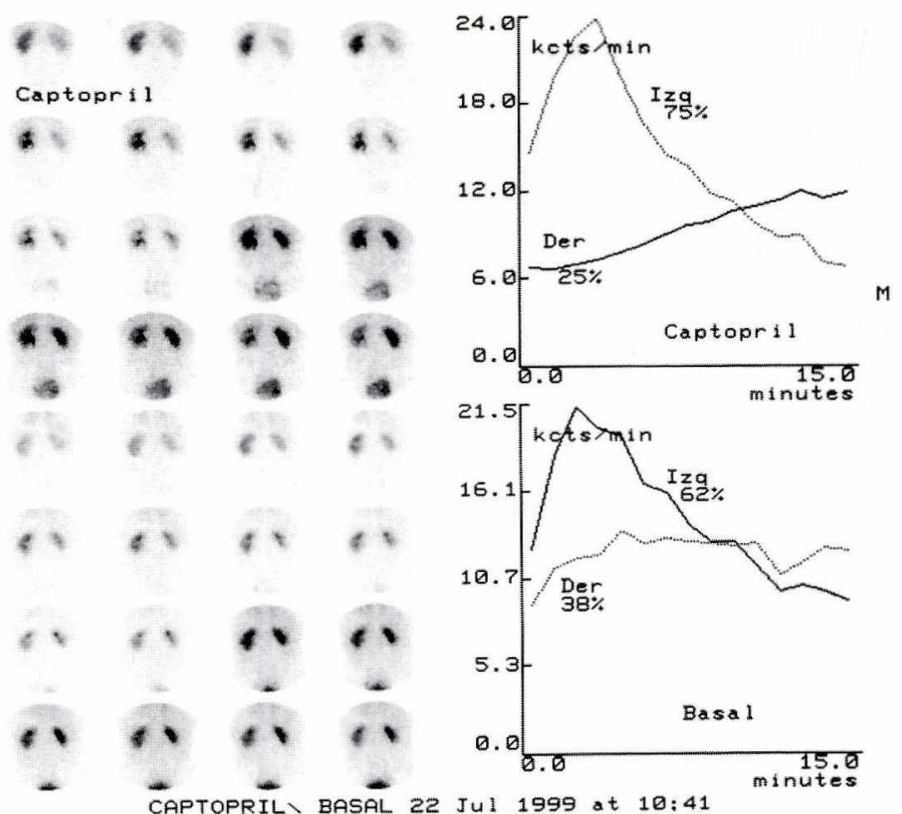

Figura 30. Renograma con captopril en un caso de nueva estenosis luego de angioplastia. La prueba vuelve a ser positiva. Luego de un período de varios meses normotenso, el paciente recae. 


\section{Sindrome escrotal agudo}

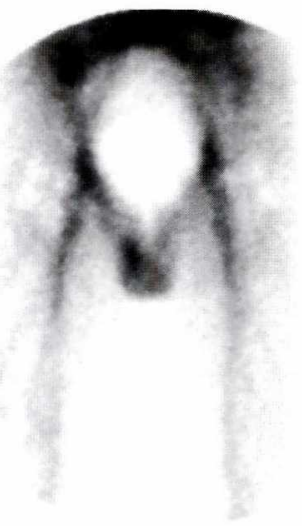

$31 a$

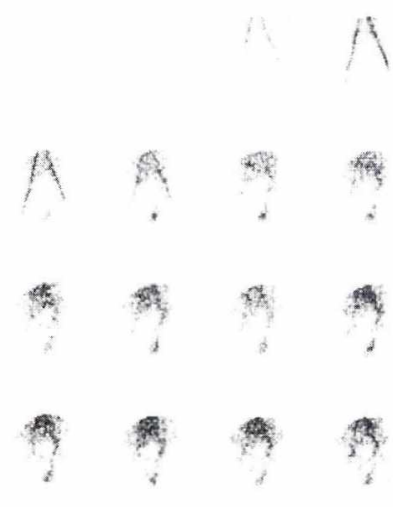

$32 a$

\section{Pielonefritis}

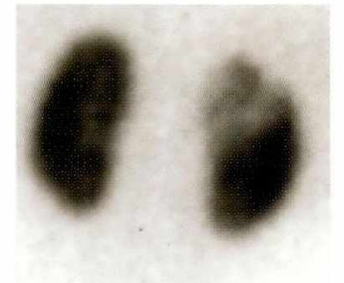

$33 a$

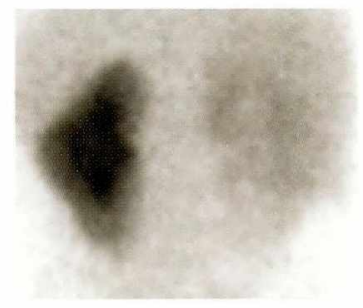

$33 e$

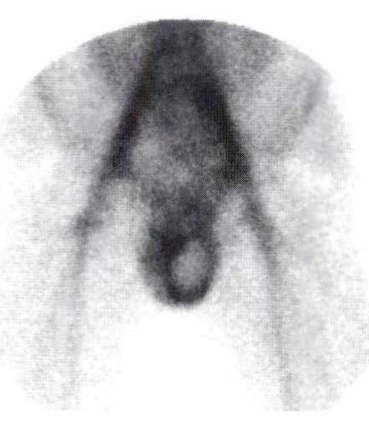

3 Ib

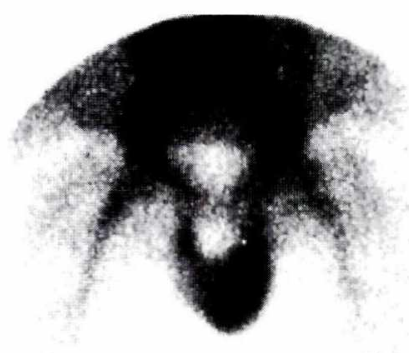

32b
Figura 31. Perfusión testicular en síndrome escrotal agudo. 3la) Torsión de la hidátide derecha en un niño de 12 años con una semana de orquialgia. 3 Ib) Torsión testicular izquierda en un adolescente de 17 años con dos días de orquialgia.
Figura 32. Perfusión testicular en orquiepididimitis izquierda, obsérvese la notoria hiperperfusión en el contenido escrotal izquierdo desde los primeros segundos (figura $32 \mathrm{a}$ ) después de la inyección, 99mTc04.

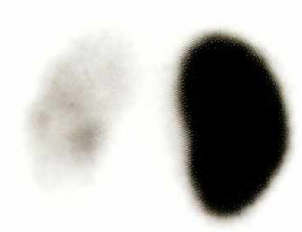

33b

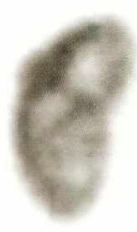

$33 f$

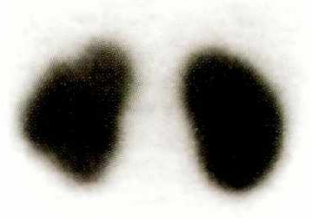

$33 c$

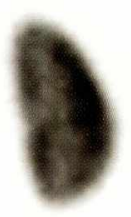

$33 \mathrm{~g}$

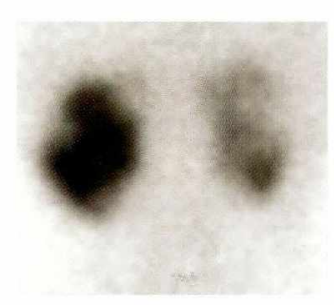

33d

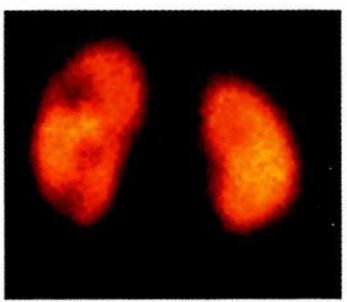

33h

Figura 33. Pielonefritis agudas con 99mTcDMSA. 33a) Focal superior derecha. 33b) Pielonefritis difusa izquierda. 33c) Focal superior izquierda y cicatriz dorsal inferior. 33d) Pielonefritis difusa derecha y multifocal izquierda. 33e) Difusa derecha asociada a HIV. 33f) Hidronefrosis izquierda asociada a infección urinaria. 33g) Infección urinaria baja por vejiga hiporrefléxica. 33h) Pielonefritis difusa. 

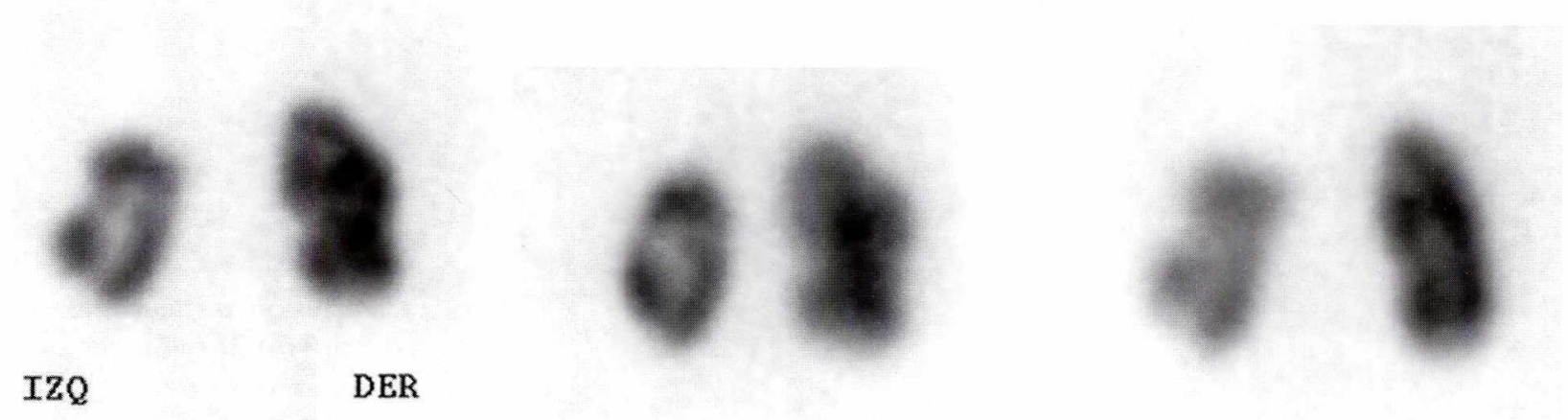

Figura 34. Cicatrices renales postinfecciosas. Observe las pérdidas de volumen renal, los contornos irregulares y la dilatación de los sistemas colectores por efecto de la nefropatía por reflujo. 99mTcDMSA. La detección de cicatrices es un signo de mal pronóstico por su carácter irreversible, la posibilidad de desarrollar hipertensión a mediano o largo plazo y eventualmente, falla renal crónica.

\section{Uropatia obstructiva}

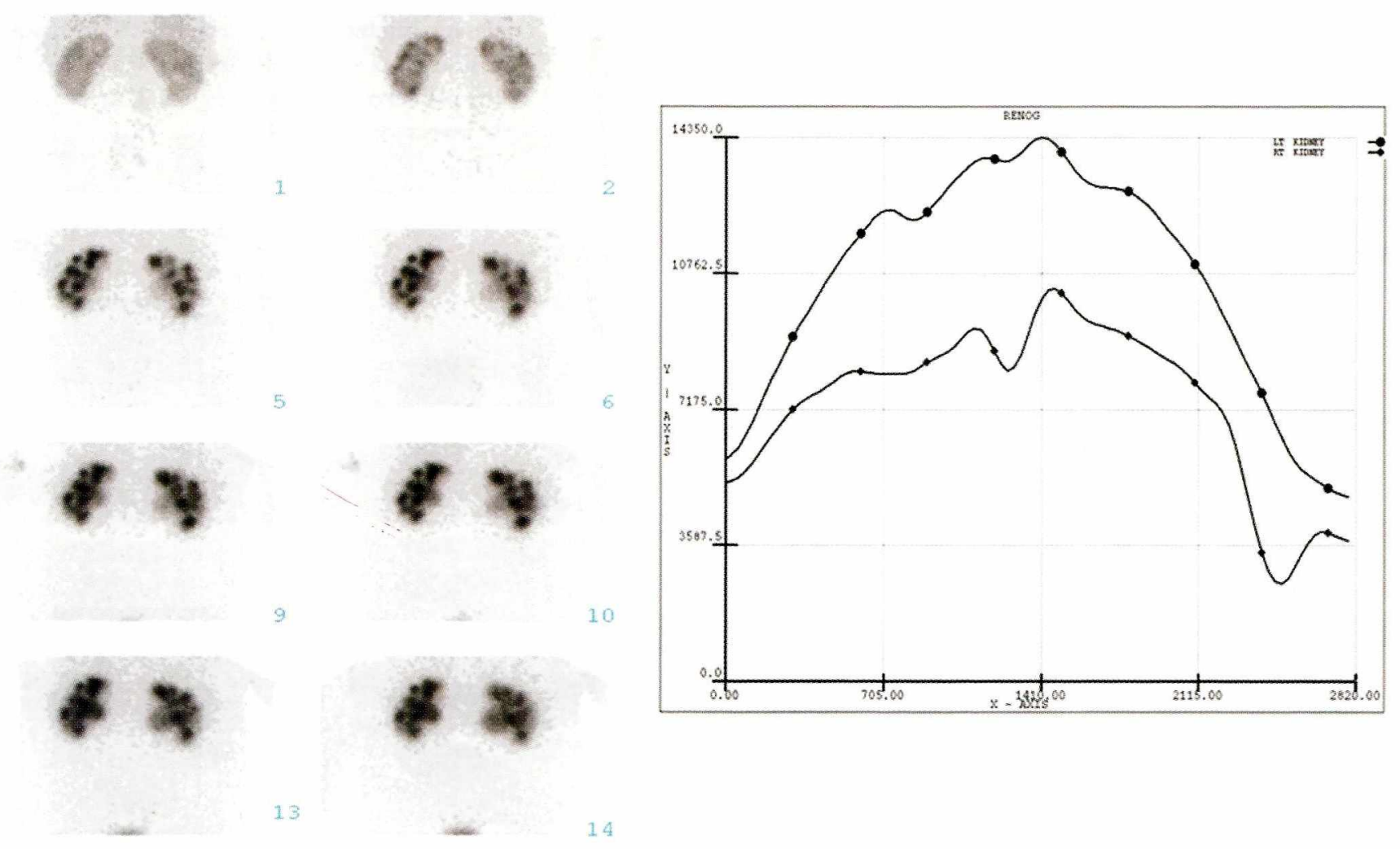

Figura 35. Uropatía obstructiva por cálculos coraliformes en hombre de 24 años, con T/2 diurético mayor de 20 minutos, 99mTcDTPA. 


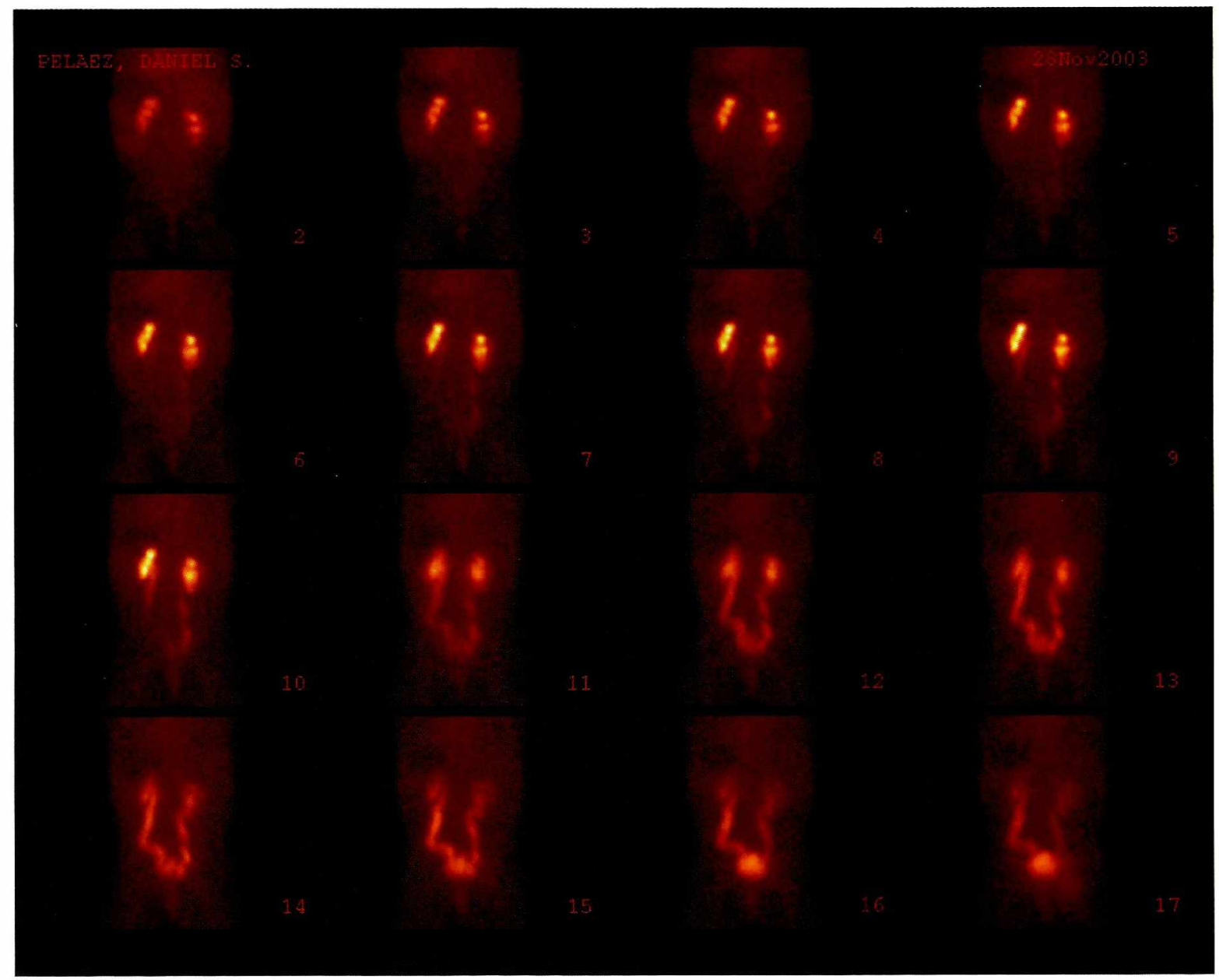

Figura 36. Ureterohidronefrosis por valvas uretrales posteriores en niño de un año luego de vesicostomía,T/2 diurético de 6 minutos, 99mTcDTPA.
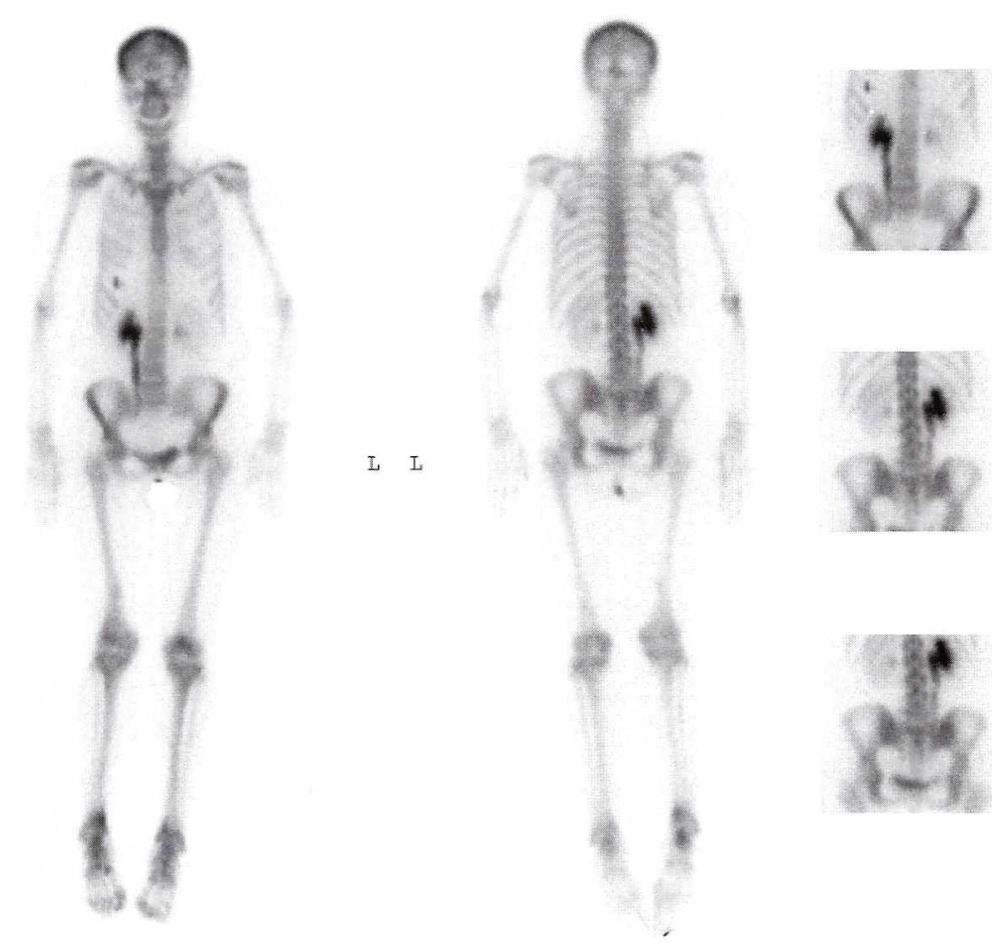

Figura 37. Uropatía obstructiva distal derecha por carcinoma de vejiga en mujer de 7 I años, gamagrafía ósea 99mTcMDP (metilén difosfonato). 

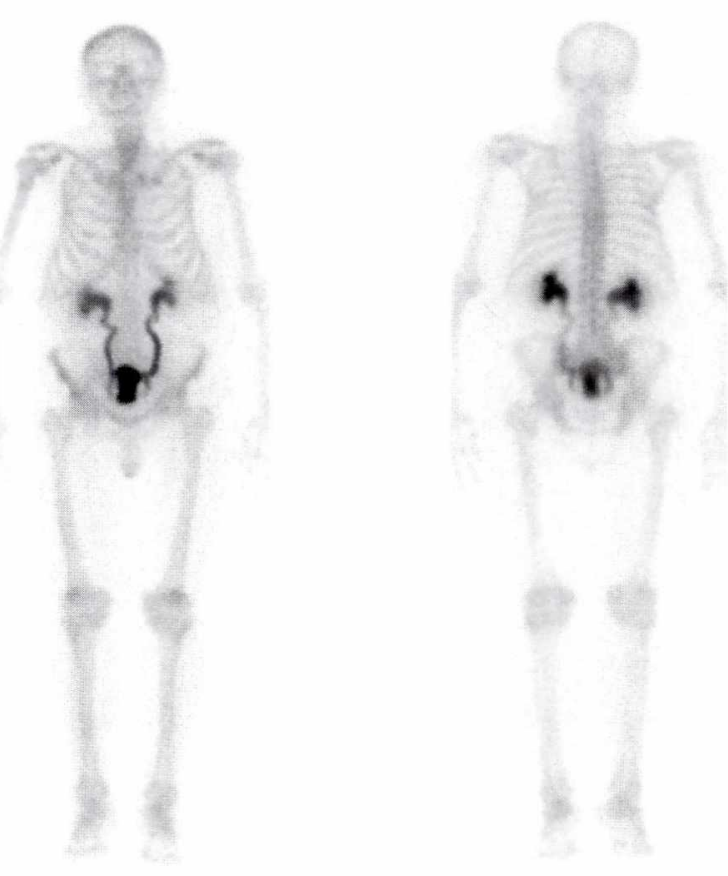
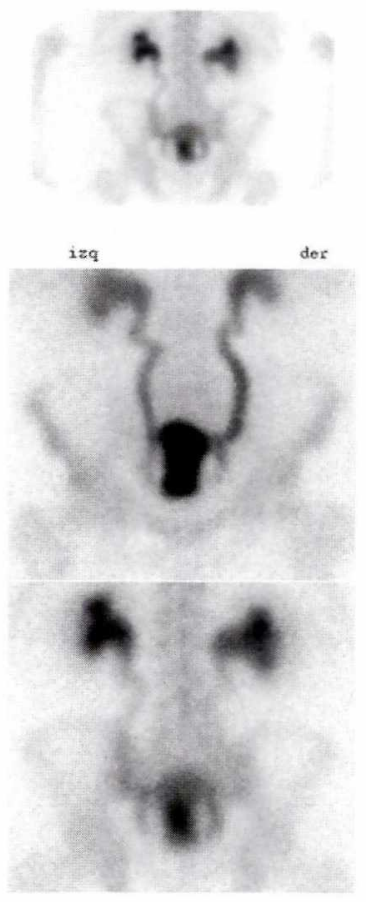

Figura 38. Uropatía obstructiva distal bilateral en recaída local de adenocarcinoma de próstata, hombre de 66 años con PSA mayor de $300 \mathrm{ng} / \mathrm{ml}$, sin metástasis óseas, $99 \mathrm{mTcMDP}$.

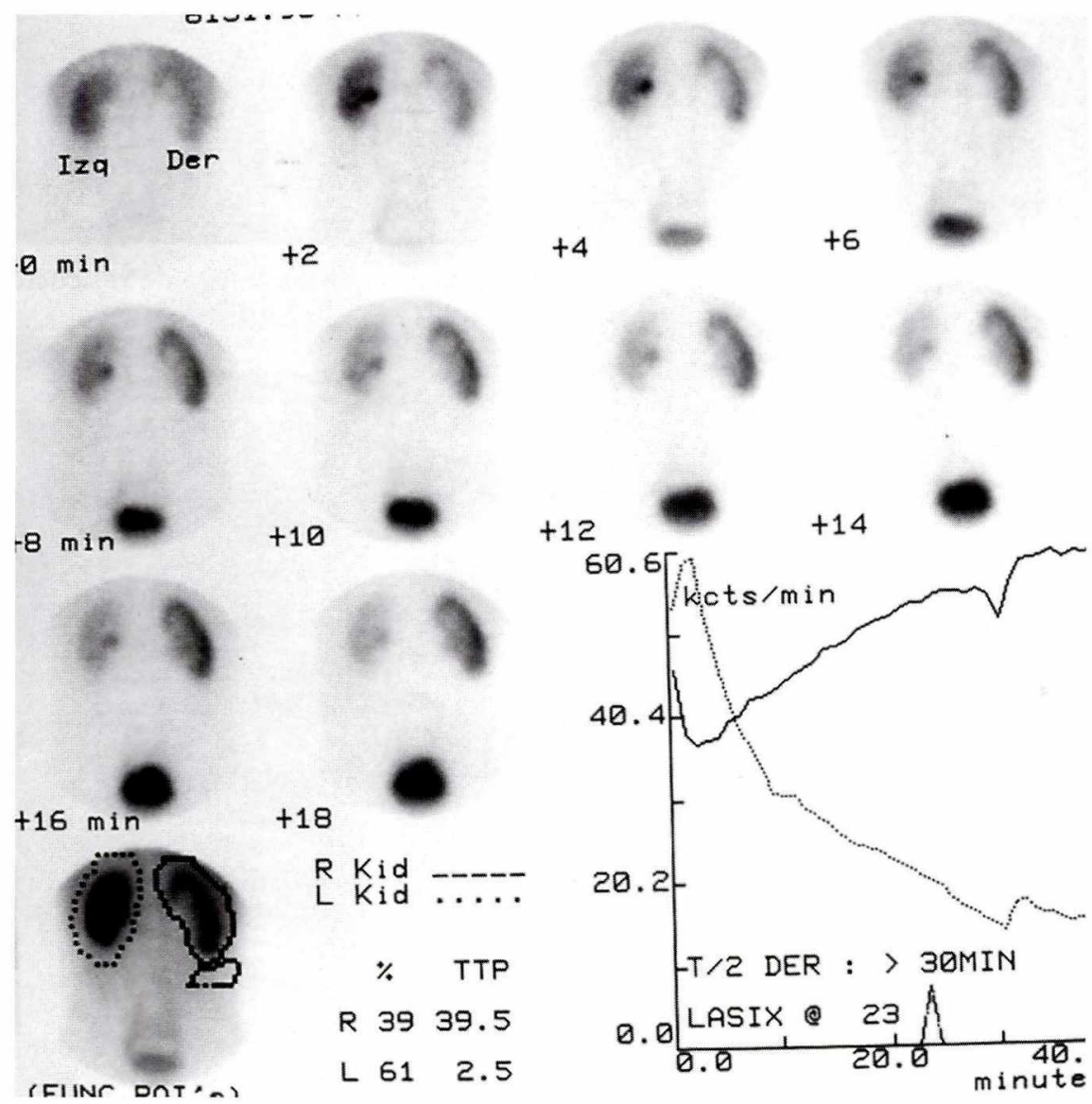

Figura 39. Renograma diurético. Está indicado en el estudio de la hidronefrosis, para establecer si es obstructiva o no. Se utiliza la furosemida endovenosa; se considera no obstructiva cuando el T/2 (tiempo al cual la radioactividad renal se reduce a la mitad) es inferior a los 10 minutos, obstructiva cuando el T/2 es mayor de 20 minutos y se le llama indeterminada o no concluyente cuando se encuentra entre los 10 y los 20 minutos. Estos valores son válidos sólo cuando la función renal es normal. 


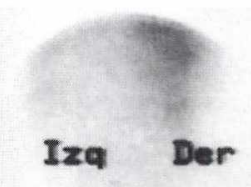

a min
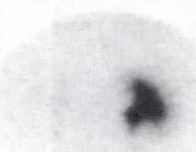

16

132

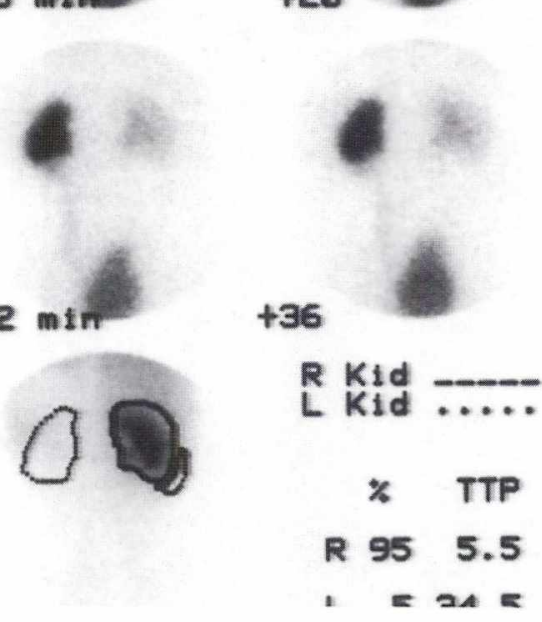

$+16 \mathrm{~min}$

$+32 \mathrm{~min}$

$+36$

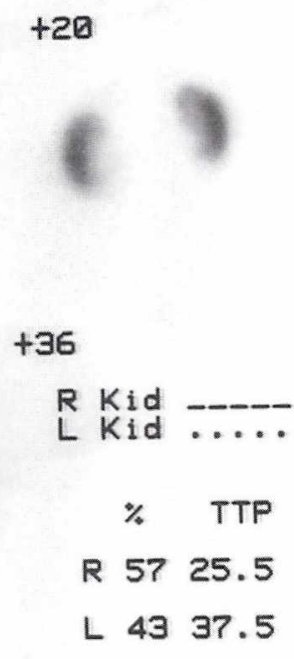

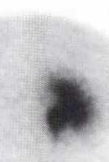

$+8$

$+12$
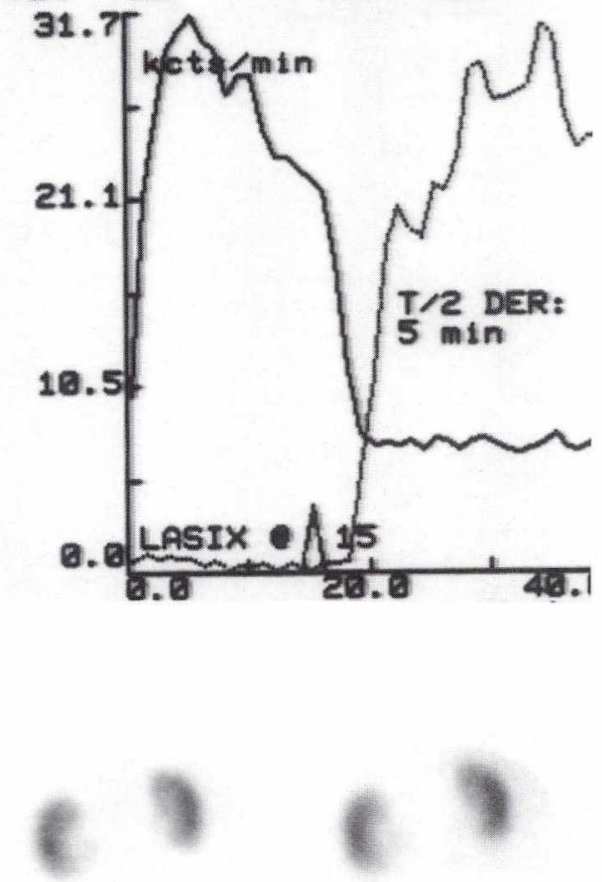

I

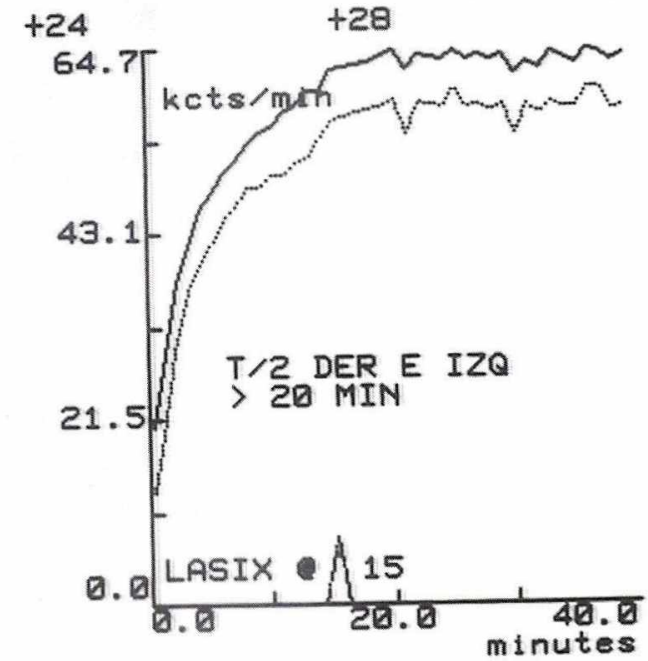

Figura 40. Exclusión funcional del riñón izquierdo en un paciente masculino de 22 años con vejiga neurogénica. Observe cómo el riñón izquierdo no aparece en los primeros minutos y súbitamente se vé, coincidiendo con la estimulación diurética con furosemida, 99mTcDTPA.
Figura 4I. Insuficiencia renal aguda secundaria a necrosis tubular aguda en postoperatorio de resección transuretral, paciente de 80 años con creatinina de $1 / \mathrm{mg} / \mathrm{dL}$. y sonda de cistostomía. Aprecie cómo el trazador permanece en la cortical, sin llenar el sistema colector y con un histograma que sugiere obstrucción aguda completa, 99mTcMAG3. 


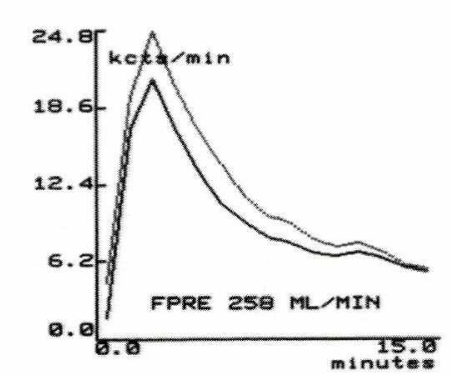

$42 a$

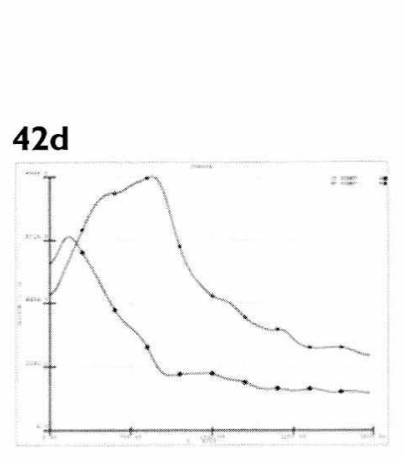

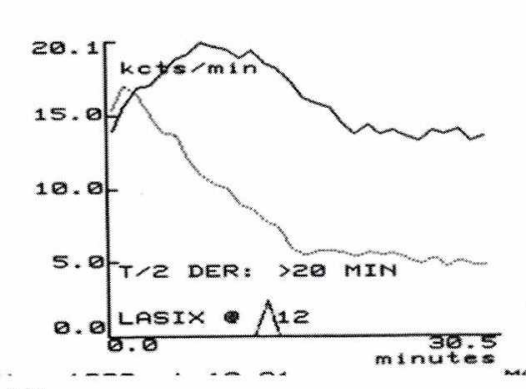

$42 b$

$42 \mathrm{e}$

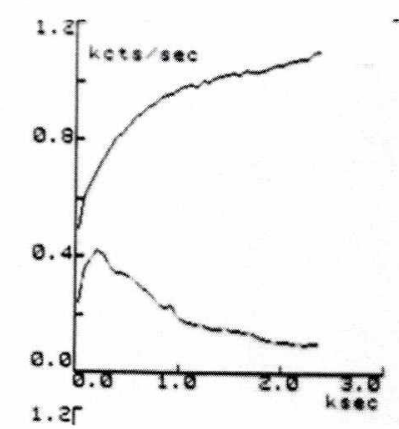

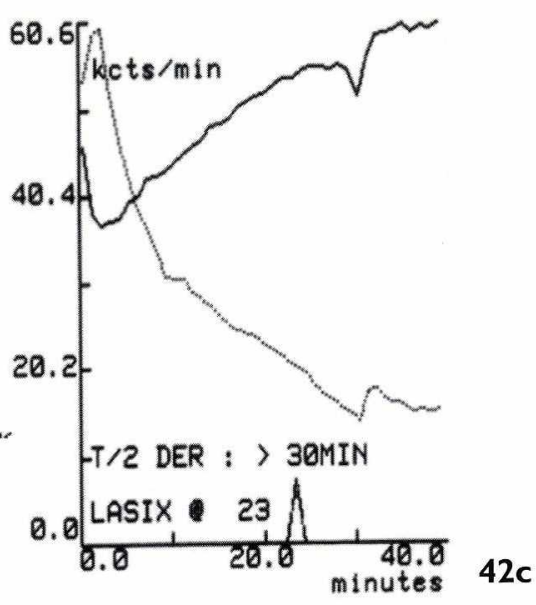

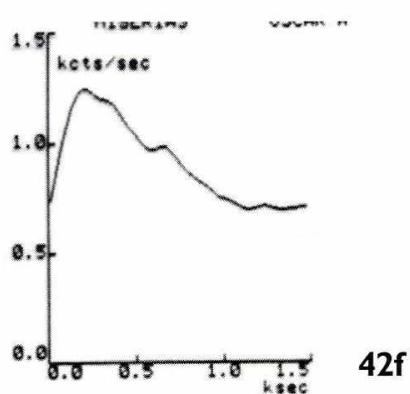

Figura 42. Histogramas. 42a) Renograma normal. 42b) Hidronefrosis con T/2 indeterminado ( 10 a 20 minutos). 42c) Hidronefrosis obstructiva con T/2 mayor de 30 minutos. 42d) Hidronefrosis no obstructiva con T/2 menor de 10 minutos. 42e) Patrón ascendente obstructivo. 42f) Patrón no obstructivo.

\section{Cáncer urogenital}
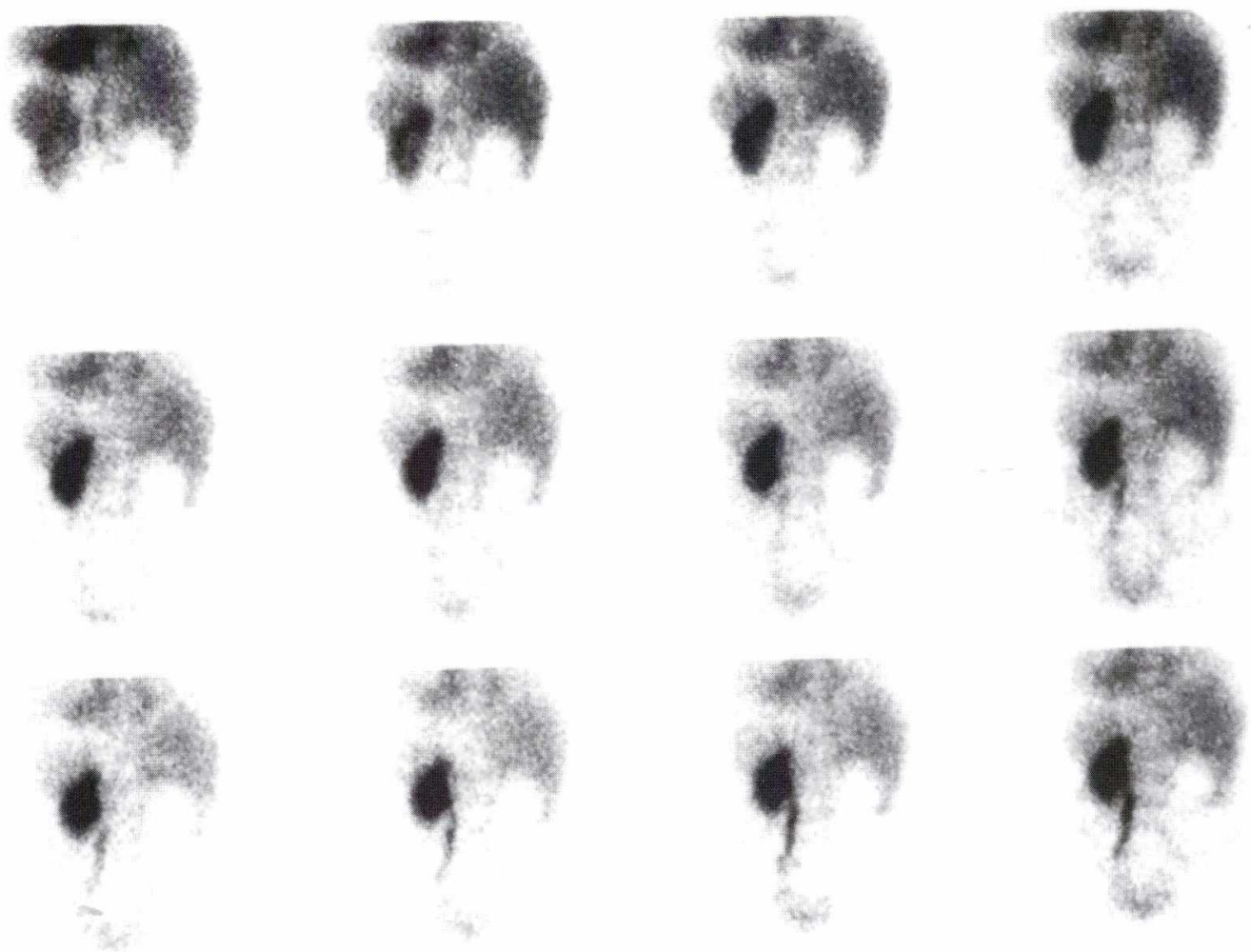

Figura 43. Falla renal por uropatía obstructiva distal por carcinoma de cervix estado IV. Observe el elevado fondo corporal radioactivo y hepático reflejando la falta de depuración del trazador, la exclusión del sistema derecho y la obstrucción distal del izquierdo. 


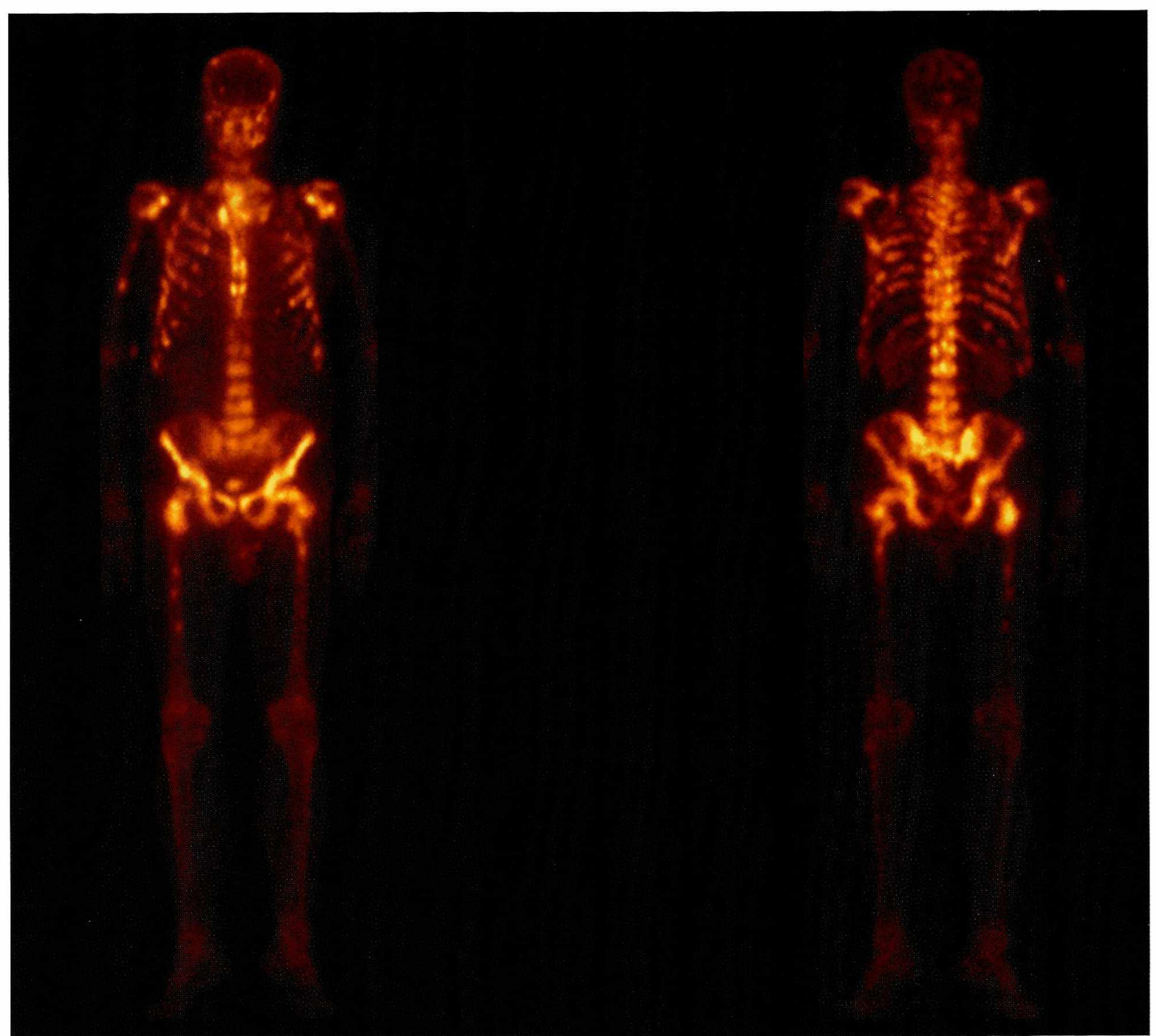

Figura 44. Metástasis esqueléticas por adenocarcinoma de próstata en hombre de 80 años, 99mTc MDP.
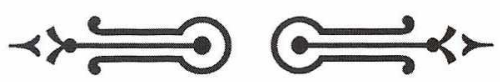